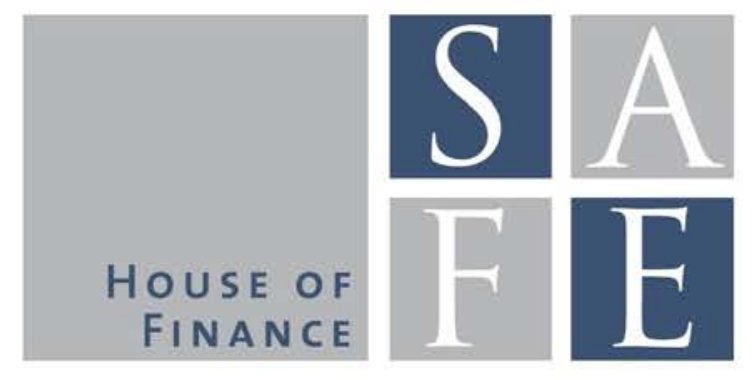

WORKING PAPER SERIES

Yalin Gündüz - Giorgio Ottonello - Loriana Pelizzon

- Michael Schneider - Marti G. Subrahmanyam

\title{
Lighting up the Dark: Liquidity in the German Corporate Bond Market
}

SAFE Working Paper No. 230

SAFE I Sustainable Architecture for Finance in Europe A cooperation of the Center for Financial Studies and Goethe University Frankfurt 


\section{Non-Technical Summary}

What is the impact of transparency on liquidity in OTC markets, both in the aggregate and at the security level? On the one hand, greater OTC market transparency reduces the asymmetry of information between dealers and investors, and encourages greater participation of retail and uninformed investors. On the other hand, improved OTC market transparency could increase transaction costs for some investors, by eliminating dealers' information rents and, thus, their incentives to compete or even participate in the market. A deeper understanding of this issue is crucial for European regulators, in light of the recent introduction of Markets in Financial Instruments Directive II (MiFID II), which has greater transparency as one of its goals.

We provide a unique study of liquidity in a market without trade transparency, and compare it to a market with full post-trade information dissemination. Specifically, we analyze the liquidity of the German corporate bond market, where there is no mandatory post-trade transparency, and compare it to the U.S. market, where the Financial Industry Regulatory Authority (FINRA) enforces a strict disclosure protocol. For our analysis, we use a unique regulatory dataset, with a complete set of bond transactions of German financial institutions from 2008 until 2014, and compare it with the Trade Reporting and Compliance Engine (TRACE) database of the U.S. corporate bond market for the same period.

Our study draws several conclusions from the detailed analysis of the two corporate bond markets, Germany and the U.S. First, overall trading activity is much lower in the German corporate bond market than in its U.S. counterpart. Second, similar to the U.S., the determinants of German corporate bond liquidity are in line with search theories of OTC markets. Third, surprisingly, frequently traded German bonds have transaction costs that are 39-61 basis points lower than a matched sample of bonds in the U.S. Our results support the notion that, while market liquidity is generally higher in transparent markets, a subset of bonds could be more liquid in more opaque markets because of investors "crowding" their demand into a small number of more actively traded securities.

Overall, our results support the notion that the effects of transparency in OTC markets are multifaceted, and not unambiguously positive. Our analysis shows that overall, transparent markets have greater trading activity and stronger participation. With greater transparency, the proportion of securities that is traded frequently is much higher, suggesting better price discovery, in the aggregate. This indicates that transparent markets are, as a whole, more liquid. However, when restricting our analysis to securities that are most frequently traded in the non-transparent market, the most similar bonds in the transparent markets could have higher transaction costs. 


\section{Nicht-technische Zusammenfassung}

Wie wirkt sich Transparenz - in der Gesamtbetrachtung wie auch auf Ebene der einzelnen Wertpapiere - auf die Liquidität an OTC-Märkten aus? Einerseits sinkt durch eine höhere Transparenz am OTC-Markt die Informationsasymmetrie zwischen Händlern und Anlegern. Zudem wird die Beteiligung von Privatanlegern und uninformierten Investoren gefördert. Andererseits könnten aufgrund der verbesserten Transparenz am OTC-Markt die Transaktionskosten für einige Investoren steigen, da die Informationsrenten der Händler wegfallen und damit deren Anreiz, miteinander zu konkurrieren oder grundsätzlich am Markt tätig zu werden. Ein besseres Verständnis dieses Themas ist für die europäischen Regulierungsbehörden von entscheidender Bedeutung, insbesondere vor dem Hintergrund der kürzlich erfolgten Einführung der Richtlinie über Märkte für Finanzinstrumente (MiFID II), deren Ziel unter anderem eine höhere Transparenz ist.

Wir untersuchen die Liquidität in einem Markt ohne Handelstransparenz und stellen diesem einen Markt mit vollständiger Informationsweitergabe im Nachhandelsbereich gegenüber. Dabei handelt es sich um die erste Studie dieser Art. Konkret analysieren wir die Liquidität des deutschen Marktes für Unternehmensanleihen, an dem keine Verpflichtung zur Nachhandelstransparenz besteht. Die Ergebnisse vergleichen wir anschließend mit dem Markt in den Vereinigten Staaten, für den die US-amerikanische Regulierungsbehörde für die Finanzindustrie (Financial Industry Regulatory Authority - FINRA) strikte Offenlegungspflichten festgelegt hat. Für unsere Untersuchung ziehen wir einzigartige aufsichtliche Daten heran, die eine komplette Reihe von Anleihetransaktionen deutscher Finanzinstitute im Zeitraum 2008 bis 2014 umfassen. Diesem Datensatz wird die „Trade Reporting and Compliance Engine" (TRACE-Datenbank) des US-amerikanischen Marktes für Unternehmensanleihen für dieselbe Zeitspanne gegenübergestellt.

Aus unserer Studie lassen sich auf Grundlage der detaillierten Analyse der beiden Märkte für Unternehmensanleihen in Deutschland und den USA mehrere Schlüsse ziehen. Erstens ist die Handelstätigkeit am deutschen Markt für Unternehmensanleihen insgesamt wesentlich geringer als an seinem US-amerikanischen Pendant. Zweitens stehen die Bestimmungsgrößen der Liquidität deutscher Unternehmensanleihen, ähnlich wie in den USA, im Einklang mit den Suchtheorien von OTC-Märkten. Drittens weisen häufig gehandelte deutsche Anleihen überraschenderweise um 39-61 Basispunkte niedrigere Transaktionskosten auf als eine abgestimmte Stichprobe von Anleihen in den Vereinigten Staaten. Unsere Ergebnisse stützen die These, dass die Marktliquidität an transparenten Märkten zwar generell höher ist, eine Teilkategorie von Anleihen an undurchsichtigeren Märkten jedoch liquider sein könnte, da die Anleger ihre Nachfrage auf eine geringe Anzahl an aktiver gehandelten Wertpapieren konzentrieren.

Insgesamt untermauern unsere Resultate die Auffassung, dass die Auswirkungen von Transparenz an OTC-Märkten vielschichtig und nicht eindeutig positiv sind. Unsere Analyse zeigt, dass transparente Märkte insgesamt durch eine höhere Handelstätigkeit und eine größere Beteiligung gekennzeichnet sind. Ist mehr Transparenz vorhanden, fällt der Anteil an häufig gehandelten Wertpapieren wesentlich größer aus, was in der Gesamtbetrachtung eine bessere Preisfindung nahelegt. Dies deutet darauf hin, dass transparente Märkte insgesamt liquider sind. Bei einer Beschränkung unserer Analyse auf Wertpapiere, die an einem intransparenten Markt am häufigsten gehandelt werden, könnten jedoch sehr ähnliche Anleihen an transparenten Märkten höhere Transaktionskosten aufweisen. 


\title{
Lighting up the Dark: Liquidity in the German Corporate Bond Market
}

\author{
Yalin Gündüz* Giorgio Ottonello ${ }^{\dagger} \quad$ Loriana Pelizzon ${ }^{\ddagger}$ \\ Michael Schneider ${ }^{\S} \quad$ Marti G. Subrahmanyam $\mathbb{I}$
}

SEPtember 17, 2018

\begin{abstract}
We study the impact of transparency on liquidity in OTC markets. We do so by providing an analysis of liquidity in a corporate bond market without trade transparency (Germany), and comparing our findings to a market with full post-trade disclosure (the U.S.). We employ a unique regulatory dataset of transactions of German financial institutions from 2008 until 2014 to find that: First, overall trading activity is much lower in the German market than in the U.S. Second, similar to the U.S., the determinants of German corporate bond liquidity are in line with search theories of OTC markets. Third, surprisingly, frequently traded German bonds have transaction costs that are 39-61 bp lower than a matched sample of bonds in the U.S. Our results support the notion that, while market liquidity is generally higher in transparent markets, a sub-set of bonds could be more liquid in more opaque markets because of investors "crowding" their demand into a small number of more actively traded securities.
\end{abstract}

Keywords: Corporate Bonds, WpHG, Liquidity, Transparency, OTC markets.

JEL Codes: G15.

\footnotetext{
${ }^{*}$ Deutsche Bundesbank; Wilhelm-Epstein-Straße 14, 60431 Frankfurt am Main, Germany; phone: +49 69 9566-8163; email: yalin.gunduz@bundesbank.de

${ }^{\dagger}$ VGSF (Vienna Graduate School of Finance); Welthandelsplatz 1, 1020 Vienna, Austria; phone: +43(1)31336 4815; email: giorgio.ottonello@vgsf.ac.at

${ }^{\ddagger}$ Goethe University Frankfurt, SAFE and Ca’ Foscari University of Venice; SAFE-Goethe University Frankfurt, Theodor-W.-Adorno-Platz 3, 60323 Frankfurt am Main, Germany; phone: +49 69 30047; email: pelizzon@safe.uni-frankfurt.de

${ }^{\S}$ Deutsche Bundesbank; Wilhelm-Epstein-Straße 14, 60431 Frankfurt am Main, Germany; phone: +49 69 9566-3592; email: schneider.michael.t@gmail.com

${ }^{\mathbb{I} Y U}$ Stern School of Business; Kaufman Management Center, 44 West Fourth Street, New York, NY 10012; phone: 212-998-0348; email: msubrahm@stern.nyu.edu

This paper represents the authors' personal opinions and does not necessarily reflect the views of the Deutsche Bundesbank, its staff, or the Eurosystem. Loriana Pelizzon and Marti G. Subrahmanyam thank the Volkswagen Stifftung Europe and Global Challenges Project, and the SAFE Center, funded by the State of Hessen Initiative for Research, LOEWE, for their financial support. Marti G. Subrahmanyam also thanks the Anneliese Maier Research Award of the Alexander von Humboldt Foundation for generous support. We acknowledge helpful comments from M. Bellia, M. Brunnermeier, W. Buehler, E. Moench and D. Tomio, and participants at the 4th SAFE Market Microstructure Workshop, Frankfurt, the International Risk Management Conference 11th edition, Paris, and the Annual Research Council Meeting of the Deutsche Bundesbank. We are responsible for all remaining errors.
} 


\section{Introduction}

One of the most interesting developments relating to the transparency of global financial markets occurred in 2002 with the launch of the Trade Reporting and Compliance Engine (TRACE) platform by the Financial Industry Regulatory Authority (FINRA) for the mandatory reporting of transactions in the over-the-counter (OTC) U.S. corporate bond market. ${ }^{1}$ However, more than 15 years after the dissemination of TRACE, the effect of transparency on liquidity and investor welfare in OTC markets is still debated. Supporters of OTC market transparency argue that it reduces the asymmetry of information between dealers and investors. Furthermore, they believe that transparency encourages the participation of retail/uninformed investors, who can benefit from better price discovery and obtain a fairer price for their transactions, similar to informed/institutional traders. ${ }^{2}$ On the other hand, OTC market transparency could increase transaction costs for some investors by eliminating dealers' information rents and, thus, incentives to compete or even participate in the market. ${ }^{3}$

In this paper, we contribute to this debate by providing a unique study of a market without trade transparency, and comparing it to one with full post-trade information dissemination. Specifically, we analyze the liquidity of the German corporate bond market, where there is no mandatory post-trade transparency, and compare it to the U.S. market, where FINRA enforces a strict disclosure protocol. For our analysis, we use a unique regulatory dataset, with a complete set of bond transactions of German financial institutions from 2008 until 2014. ${ }^{4}$ To the best of our knowledge, we are the first researchers to use this database to study market liquidity. Therefore, we provide a detailed description of our data cleaning procedures, which determine our sample selection. We focus on straight, unsecured corporate bonds, excluding all bonds with complex embedded optionalities. We estimate transaction

\footnotetext{
${ }^{1}$ The TRACE platform was extended to other U.S. fixed-income markets, including the structured product market in May 2011 (see Friewald, Jankowitsch, and Subrahmanyam (2017)), and most recently, the Treasury bond market in July 2017.

${ }^{2}$ For theoretical work on OTC market transparency, see Pagano and Roell (1996), Duffie, Dworczac, and Zhu (2017), Asriyan, Fuchs, and Green (2017). Empirical analysis supporting these arguments can be found in Bessembinder, Maxwell, and Venkataraman (2006), Edwards, Harris, and Piwowar (2007).

${ }^{3}$ See Naik, Neuberger, and Viswanathan (1999), Bloomfield and O'Hara (1999), Holmstrom (2015), Bhattacharya (2016).

${ }^{4}$ Reporting is mandated through the German Securities Trading Act, (Wertpapierhandelsgesetz, "WpHG" for short) and collected by the German federal financial supervisory authority Bundesanstalt für Finanzdienstleistungsaufsicht, "BaFin" for short.
} 
costs at a weekly frequency by adopting a wide range of liquidity measures. Starting with a sample of 11,670 corporate bonds, we focus on a relatively liquid sample in which a particular bond trades at least 8 times in a week. Our final sample includes 1,703 corporate bonds for the German market (1,585 issued by financial institutions and 118 issued by non-financial firms).$^{5}$

Our study consists of four parts. First, we provide a general description of the German corporate bond market, focusing on the key characteristics of the bonds in our sample and their trading activity. Second, we analyze the time-series evolution of liquidity in the German market. Third, we study the determinants of liquidity in a cross-section of the German bond market with panel regressions on bond characteristics in the spirit of Edwards, Harris, and Piwowar (2007). Fourth, we use a matched-sample approach to compare the transaction costs of similar bonds, at the same point in time, in the German and the U.S. market respectively. The variables that we use for our matching procedure are coupon, rating, time to maturity, size, volume traded and trading frequency.

In our descriptive analysis, we find significant differences between the German and U.S. markets. The former is composed, in great part, of financial bonds (i.e. bonds issued by financial firms, or financials), which are ten times as numerous as non-financial bonds (i.e. bonds issued by non-financial firms, or non-financials). In the U.S. market, financials are also in the majority, but are just four times as numerous as non-financials. Bond characteristics present differences as well in our sample: German bonds have a higher coupon, a lower time to maturity than their U.S. counterparts; moreover most of the non-financial bonds are unrated. Observed trading activity is much lower in the German market: (i) overall trading activity is about 5 times lower for German financial bonds than in the U.S., adjusting for the amount outstanding, and $25 \%$ lower for the non-financial bonds; (ii) the bonds that traded 8 times per week at least once are only $17 \%$ of the sample, against $74 \%$ of the traded sample in the U.S. TRACE universe. Looking at the market as a whole, liquidity is clearly much higher in the U.S., with a significantly larger number of securities that trade often and, therefore, are likely to provide more informative prices. This result is consistent with various theoretical

\footnotetext{
${ }^{5}$ Of the starting sample, 9,741 are those issued by German corporations.
} 
studies that show that transparency lowers costs for unsophisticated investors and, therefore, incentivizes participation in the market. ${ }^{6}$

On top of the transparency issue, it is important to consider that the credit market structure in Europe relies heavily on loan financing, which explains the relatively lower total amount outstanding of European corporate bonds compared to the U.S. ${ }^{7}$ The disparity in trading activity between Europe and the U.S. can be partially explained by the fact that European corporate bonds are often held until maturity by long-term investors such as insurance companies. In addition, there is a strong home bias particularly among retail investors, accentuated by concerns about taxation, bankruptcy law and market frictions.

Despite the differences in trading activity and overall size, the time-series dynamics of liquidity looks similar between the two markets, across different liquidity measures. As expected, we find that transaction costs for German corporate bonds spiked during the 2008-2009 global financial crisis and the sovereign debt crisis in 2011-2012. While the former clearly affected liquidity in the U.S. market as well, as documented by Friewald, Jankowitsch, and Subrahmanyam (2012) and others, the latter did not and, thus, was a shock mostly limited to the euro area, and perhaps the rest of Europe. Our cross-sectional analysis shows that the relations predicted by search theories of OTC markets are also confirmed in the German market. A bond is more liquid if it has a larger issue size, a better credit rating, a shorter time to maturity, a younger age, and a larger volume traded.

Our matched-sample analysis allows us to compare frequently traded German bonds with a group of U.S. bonds that have similar characteristics, at the same point in time. Contrary to our expectations, across all the liquidity measures except imputed round-trip cost, we find that this group of German bonds has significantly lower transaction costs than comparable bonds in the U.S. market. The difference in round-trip costs is within a range of 39-61

\footnotetext{
${ }^{6}$ For theoretical studies, see for example Pagano and Roell (1996), Duffie, Dworczac, and Zhu (2017).

${ }^{7}$ Celent (2013) in a study on the evolution of global debt outstanding in Europe and the U.S. shows that, in 2009, the amount outstanding of corporate bonds in Europe including the U.K. is EUR 11.1 trillion in financial and EUR 1.3 trillion in non-financial firms, compared to EUR 12.6 trillion and EUR 3.5 trillion respectively in the U.S. In March 2012, these numbers increased to EUR 11.8 trillion and EUR 1.6 trillion respectively for financial and non-financial firms in Europe, as against EUR 10.7 trillion and EUR 4.4 trillion respectively in the U.S. For the euro area, the amount outstanding in December 2012 is EUR 11.7 trillion and EUR 1.6 trillion respectively for financial and non-financial firms. (The numbers have been converted into EUR at the average exchange rate of 1.36 USD per EUR.)
} 
basis points, depending on the liquidity measure used. This finding might seem surprising, at first blush. However, it is in line with studies that highlight the potential unintended consequences of an increase in transparency in OTC markets. For example, Naik, Neuberger, and Viswanathan (1999) show that, in a more transparent market, dealers fail to extract information rents from trading with investors and have less incentive to compete, which could lead to higher costs of trading for investors. Bloomfield and O'Hara (1999) provide similar findings in a laboratory experiment. In a recent study, Bhattacharya (2016) shows how post-trade transparency can increase transaction costs due to trade delays by investors who wait longer in order to acquire more information by monitoring disseminated trade prices. In a similar vein, Friewald, Jankowitsch, and Subrahmanyam (2017) document in the U.S. securitized product market that there is an optimal level of detail in disclosure, beyond which there is no improvement in liquidity. Given this prior research, a possible explanation for our finding is that, when there is little transparency, investors concentrate their demand into a few well-traded assets, resulting in "crowding". As a consequence, the liquidity of these few bonds is particularly high, while the others are barely traded, resulting in a greater dispersion of liquidity across bonds. An alternative, symmetric explanation could be that market makers find it difficult to provide liquidity beyond a small number of instruments when transparency is low overall. In either case, lower transparency leads to "crowding" of demand into a few securities that may be even more liquid as a consequence. On the other hand, when overall transparency increases, investors spread their portfolios across a wider range of assets, given the higher level of information available. While the overall market liquidity improves, there is less relative demand for the previously "well-traded assets", and hence their transaction costs could, in fact, be higher, at least in some cases.

Overall, our results support the notion that the effects of transparency in OTC markets are multifaceted, and not unambiguously positive. Our analysis shows that transparent markets have greater trading activity and stronger participation overall. With greater transparency, the proportion of securities that is traded frequently is much higher, suggesting better price discovery overall. This indicates that transparent markets are, as a whole, more liquid. However, when restricting our analysis to securities that are most frequently traded in the 
non-transparent market, the most similar bonds in the transparent markets could have higher transaction costs.

Our paper makes three main contributions. First, it adds to the debate on the effect of transparency in OTC markets by providing a novel analysis of a market without post-trade transparency. Many empirical studies have analyzed the impact of transparency in the U.S. market, using different phases of the TRACE program for identification. However, such analyses cannot overcome the limitation that the assets still belong to the same overall market, which does not allow cross-market comparisons. In contrast, our access to a novel database allows us to analyze, in detail, the German market without transparency, and compare it with the U.S. market with mandatory disclosure. Second, it presents a comprehensive analysis of the liquidity of a rather unexplored market which is growing and is among the largest European bond markets. Third, our paper provides a detailed description of a filtering procedure for a new database which has potential for future research on other illiquid bond markets, or for answering policy questions regarding the German bond market. Our results are of interest for academics and regulators alike. In particular, they address the recent debate on the introduction of MiFID II and MiFIR, and provide a perspective on how to critically evaluate the anticipated improvement in transparency in European fixed-income markets. ${ }^{8}$

The paper is organized as follows. Section 2 provides a literature review. Section 3 describes the corporate bond market structure in Europe. Section 4 introduces our dataset and describes our approach to obtaining samples, for which we provide descriptive statistics. In Section 5, we use various liquidity measures from the literature in order to examine the time-series evolution of liquidity, study the determinants of liquidity in the cross-section with panel regressions and to compare the transaction costs of similar bonds, at the same point in time, in the German and the U.S. market with a matched-sample approach. Section 6 concludes.

\footnotetext{
${ }^{8}$ In an attempt to increase transparency, the European Parliament and the European Council approved in 2014 Notification 2014/65/EU - Markets in Financial Instruments Directive II (MiFID II) and Regulation (EU) No. 600/2014 - Markets in Financial Instrument Regulation (MiFIR), to enhance pre- and post-trade transparency of both equity and non-equity instruments and derivatives including fixed-income bonds, which have been applicable to all European markets since January 3, 2018.
} 


\section{Literature Review}

\subsection{The European Corporate Bond Market}

A number of papers in the literature deal with the pricing of European corporate bonds in relation to credit risk and other risk factors and illiquidity risk at the aggregate level. Others provide a description of the vast cross-section of yields. However, none of them provide an analysis of liquidity at the issue level, since they do not employ a dataset nearly as complete and detailed as ours. A few studies employ transaction data, e.g. Díaz and Navarro (2002), use data of trades in 1993-1997 on three Spanish bond platforms, and Frühwirth, Schneider, and Sögner (2010) use closing prices from transactions on German exchanges. Other articles (Houweling, Mentink, and Vorst (2005); Van Landschoot (2008); Castagnetti and Rossi (2013); Klein and Stellner (2014); Utz, Weber, and Wimmer (2016)) rely on yield quotes, e.g. from Bloomberg, at daily or lower frequencies or consider corporate bond indices (Aussenegg, Goetz, and Jelic (2015)).

Two papers shed light on the market microstructure of specific trading platforms for corporate bonds: Fermanian, Guéant, and Pu (2016) model the request-for-quote (RFQ) process on the multi-dealer-to-client platform, Bloomberg FIT, based on a fraction of the RFQs received by BNP Paribas in the years 2014 and 2015. However, their focus is on the behavior of clients and dealers rather than on the market as a whole, with the data being used to calibrate their theoretical model. In fact, no statistics on trading volumes or liquidity measures are provided, since that is not their focus. Linciano, Fancello, Gentile, and Modena (2014) study the liquidity of Italian corporate bonds that are listed on two platforms contemporaneously (DomesticMOT or ExtraMOT and EuroTLX) and find a mixed impact of such fragmentation. Also, their analysis is restricted to these platforms and neglects the major market share of OTC voice trades, which form the majority of trades in corporate bond markets. A different approach is taken in Deutsche Bundesbank (2017), which mainly considers the market size of bonds of non-financial corporations in the euro area in terms of the total amount outstanding. The report analyzes the bond market in the context of the low-interest-rate environment of the past few years based on supply and demand factors, 
looking at issued amounts, yields and yield spreads of corporate bond indices. ${ }^{9}$

Biais, Declerck, Dow, Portes, and von Thadden (2006) investigate liquidity based on a dataset of interdealer trades from 2003 to 2005 in a set of euro- and sterling-denominated bonds listed in the iBoxx index by looking at quoted and effective bid-ask spreads. Furthermore, the paper considers informational efficiency in the European bond markets and compares it to the early literature on the U.S. TRACE database. However, it refers to the market before the global financial crisis and the European sovereign debt crisis, and the consequent changes in market regulation are not reflected therein.

Our study, in contrast, is based on a broader dataset, both in terms of transaction detail and the underlying bond universe, and provides a direct comparison with the U.S. TRACE database. Finally, in our analysis of liquidity, we not only rely on quoted spreads and prices but employ a range of liquidity measures based on actual transactions that have proven more suitable for the analysis of OTC markets. We are aware of only two other studies that make use of regulatory trade-level data to study liquidity in European bond markets: Autorité des Marchés Financiers (2015) studies the French bond market and aims primarily at constructing a composite liquidity indicator. Aquilina and Suntheim (2017) provide a similar analysis for the U.K. corporate bond market, likewise quantifying the yield spread due to liquidity. ${ }^{10}$ It should be emphasized that none of these studies takes into account bond characteristics as drivers of liquidity and their evolution over time, nor do they make a comparison against the benchmark U.S. market.

\subsection{The U.S. Corporate Bond Market}

Since the inception of TRACE in July 2002, there has been a growing number of empirical studies that analyze the U.S. corporate bond market. Among the first of these after the introduction of post-trade transparency are Bessembinder, Maxwell, and Venkataraman (2006)

\footnotetext{
${ }^{9}$ An earlier study in this direction is Pagano and Von Thadden (2004), in the context of the monetary unification of the euro area.

${ }^{10}$ Another regulatory report that is concerned with the corporate bond market at the European level is European Securities and Markets Authority (2016); however, it relies on data from Markit and Euroclear, both based on market averages, instead of transactions-level data. Also Todorov (2017) uses Euroclear data to study the impact of ECB's corporate bond purchase program (CSPP) on turnover and issuance of corporate debt.
} 
and Edwards, Harris, and Piwowar (2007). ${ }^{11}$ Both papers focus on the effect that post-trade transparency has on corporate bond transaction costs, finding that bid-ask spreads reduced significantly after the introduction of TRACE. Edwards, Harris, and Piwowar (2007), moreover, provide an analysis of trading costs on the cross-section of bonds, showing that those that are better rated, recently issued and close to maturity are more liquid. In a more recent paper, Bao, Pan, and Wang (2011) focus on the link between illiquidity and pricing in the U.S. corporate bond market, showing that a significant part of the variation of yield spreads can be explained by movements in market illiquidity. Along the same lines, Lin, Wang, and Wu (2011) find a robust link between illiquidity and corporate bond returns. Liquidity can be an issue, especially during periods of financial distress, either at the market or at the security level. The two most prominent papers analyzing U.S. corporate bond market liquidity during the financial crisis are Friewald, Jankowitsch, and Subrahmanyam (2012) and Dick-Nielsen, Feldhütter, and Lando (2012), who show that trading costs spiked during the recent financial crisis, thus having a significant impact on yield spreads, especially those of bonds with high credit risk. Jankowitsch, Nagler, and Subrahmanyam (2014) focus on the effects of financial distress on liquidity at the security level, analyzing the recovery rates of defaulted bonds. A more recent group of papers focuses on the impact of the Volcker rule on the U.S. corporate bond market liquidity. As pointed out by Duffie (2012b), the restriction imposed by regulators on dealers' trading activity can significantly affect the level of the bid-ask spreads in the market. Bessembinder, Jacobsen, Maxwell, and Venkataraman (2018) study corporate bond liquidity and dealer behavior in the period 2006-2016, finding that trade execution costs have not increased significantly over time, while dealer capital commitment to market making was significantly reduced after the crisis. Bao, O'Hara, and Zhou (2018) analyze the illiquidity of stressed bonds, focusing on rating downgrades as stress events. They find that, after the introduction of the Volcker Rule, stressed bonds are significantly more illiquid due to Volcker-affected dealers lowering their market liquidity provision. Finally, in a recent working paper, Choi and Huh (2018) demonstrate that customers, such as hedge funds, often provide liquidity in the post-crisis U.S. corporate bond market. Therefore, average bid-ask spreads,

\footnotetext{
${ }^{11}$ Harris and Piwowar (2006) provide a similar study for the municipal bond market.
} 
which rely on the assumption that dealers provide liquidity underestimate trading costs that liquidity-demanding investors pay. Finally, Schestag, Schuster, and Uhrig-Homburg (2016) provide a comprehensive analysis of liquidity measures in OTC bond markets using a sample period that covers 2003-2014.

\section{$3 \quad$ Market Structure and Financial Market Regulation}

From the market microstructure point of view, the European corporate bond market is mostly a classic over-the-counter (OTC) market. ${ }^{12}$ This OTC market is further differentiated by size, and involves an inter-dealer segment (i.e. D2D) and a retail segment (dealer-customer, i.e. D2C), and into voice and electronic markets, by trading mechanism. The voice market is organized around dealers (large banks and securities houses) and their network of clients. Transactions are largely bilateral via the telephone. As stressed in Duffie (2012a), the process of matching buyers and sellers requires a large amount of intermediation in this market, as well as attendant search costs. Since this market is known as a quote-driven market, i.e. executable prices are offered in response to a counterparty's request to trade, prices for the same bond, at the same time, could vary significantly across dealers; hence, traders often contact more than one dealer in search of the best execution price. This, and the fact that quotes and transaction prices are usually not publicly known, make bond trading more opaque than many other traded asset classes and allows price discrimination.

Besides voice trading, there exist several electronic platforms with different trading protocols at their core. Single-dealer platforms are often merely an electronic version of the voice mechanisms described above, while multi-dealer platforms allow the customer to request quotes to trade from a number of dealers simultaneously and facilitate automated record keeping. Another recent innovation is "all-to-all" platforms, which are estimated to account for almost $5 \%$ of electronic trading so far. For a survey of the ongoing developments that are

\footnotetext{
${ }^{12}$ Even in cases where exchanges are organized around a central limit order book, their market share is minor. For example, in the Italian bond market, where exchange trading is relatively more common, less than $30 \%$ of the turnover in Italian non-government bonds takes place on exchanges, according to a report by the Italian securities regulator Commissione Nazionale per le Società e la Borsa (CONSOB, Bollettino Statistico Nr. 8, March 2016, available at http://www.consob.it/web/area-pubblica/bollettino-statistico), with the rest occurring in the OTC market. This number is likely to be much lower for other European countries, including Germany.
} 
affecting the market structure and functioning of the fixed-income markets due to electronic trading, see Bank for International Settlements (2016). A study by Greenwich Associates (Greenwich Associates (2014)) indicates that around 50\% of trading volume is conducted electronically in the European investment grade corporate bond market, and almost $20 \%$ in the case of high-yield bonds.

\section{Data}

\subsection{Description of the Dataset}

Our dataset is based on the transaction reporting obligations of German banks mandated by the German Securities Trading Act (Wertpapierhandelsgesetz, "WpHG"). Section 9 of the act, further detailed in the respective regulation (Wertpapierhandel-Meldeverordnung, "WpHMV"), requires credit or financial services institutions, branches of foreign institutions and central counterparties (only Eurex Clearing AG, in practice) domiciled in Germany to report to the German Federal Financial Supervisory Authority (Bundesanstalt für Finanzdienstleistungsaufsicht, popularly known as "BaFin"). The requirement is to report "any transactions in financial instruments which are admitted to trading on an organised market or are included in the regulated market (regulierter Markt) or the regulated unofficial market (Freiverkehr) of a German stock exchange". The dataset also captures a large set of transactions of non-German institutions at German exchanges. ${ }^{13}$

To the best of our knowledge, this dataset has only been used in a set of studies in the context of institutional herding in the German equities market (Kremer and Nautz (2013a), Kremer and Nautz (2013b), and Boortz, Kremer, Jurkatis, and Nautz (2014)). Since these prior studies offer neither a comprehensive description of the dataset nor a focus on corporate bonds, we initially provide a detailed description of the dataset and the series of filtering steps we apply to the raw data. The transactions dataset contains security information, detailed information on the transaction (for instance, time, price, size, exchange code or in-

\footnotetext{
${ }^{13}$ Building societies (Bausparkassen) are excluded from the reporting requirement. Moreover, non-German EU banks do not have to report trades in MiFID-securities since they already report these in their home countries. A non-binding English translation of the law is provided at https://www.bafin.de/SharedDocs/ Veroeffentlichungen/EN/Aufsichtsrecht/Gesetz/WpHG_en.html
} 
dicator for OTC trades) and the parties involved (an identifier for the reporting institution and, where applicable, identifiers of client, counterparty, broker or intermediaries). ${ }^{14}$ We augment this information with security characteristics from the Centralized Securities Database (CSDB), which is operated jointly by the members of the European System of Central Banks (ESCB), together with other security information from Thomson Reuters, Datastream and Bloomberg. For a smaller subset of bonds, we also obtained time series of daily price quotes from Bloomberg.

Our raw dataset contains all reporting in "any interest-bearing or discounted security that normally obliges the issuer to pay the bondholder a contracted sum of money and to repay the principal amount of the debt" as indicated by a CFI code starting with "DB" (with "D" for debt instruments, and "B" for bonds). ${ }^{15}$ Our bond dataset covers the full set of transactions over the period from January 2008 to December 2014; therefore, it initially includes any type of sovereign, guaranteed, secured, unsecured, negative pledge, junior/subordinated and senior bonds reported through $\mathrm{WpHG} .{ }^{16}$ For this sample selection, we adopt a narrower definition of the corporate bond market than Deutsche Bundesbank (2017) and the capital market statistics of the Deutsche Bundesbank, which include other debt-type securities not classified as bonds. In addition, we note that our initial sample includes non-German bonds (traded by German financial institutions) as well.

\subsection{Data Filtering and Sample Selection}

Our dataset is subjected to a careful filtering process in order to ensure the soundness and reliability of the final sample. We describe below our general procedure, also mentioning considerations for uses of the data other than the analysis in this paper. We then proceed to describe the sample selection filters that are specific to our paper.

\section{Insert Table 1 here.}

\footnotetext{
${ }^{14}$ For a full list of variables, see the Annex to WpHMV. A non-binding English translation is provided at https://www.bafin.de/SharedDocs/Downloads/EN/Formular/WA/dl_wphmv_anlage_en.html

${ }^{15}$ This definition excludes any convertible bonds ("DC"), bonds with warrants attached ("DW"), mediumterm notes ("DT"), money market instruments ("DY"), asset-backed securities ("DA"), mortgage-backed securities ("DG"), or other miscellaenous debt instruments ("DM").

${ }^{16}$ Our sample does not include Schuldscheine, which are similar to bonds without being a security, and are not registered at a stock exchange.
} 
Panel A of Table 1 provides an overview of the observations discarded throughout the cleaning process. In a first cleaning step, we remove entries with invalid ISINs or timestamps. Moreover, we employ an error code assigned by BaFin to each observation, which takes the integer values from 0 (no errors) to 3 (serious errors - junk), to drop observations with error code 3 in this step. On average, this step filters out only $0.2 \%$ of observations, and we observe that the data quality improves after 2009. Recall that the initial filtering of our dataset for bond-type securities relied on the CFI code provided by the reporting institutions. In the second step, to ensure robustness of our data, we also remove all observations from ISINs where the CFI code recorded by CSDB does not start with "DB", thus double-checking our sample selection. This removes another $5.0 \%$ of our initial observations. Prices are reported in the currency used in the trade and need to be converted to EUR. In the third step, we do so by keeping only trades originally reported in the main currencies: "EUR", "AUD", "CHF", "GBP", "USD", "CAD", "JPY", "DKK", "NOK" and "SEK".

In the fourth step, we remove so-called technical lines. These lines are created in some reporting systems e.g. when a trade is on hold while a broker is gathering more of a security she has committed to sell. Technical lines are detected when the reporting entity field is identical to the client field. Discarding them removes $37.6 \%$ of the initial number of observations. Even after accounting for technical lines, the same transaction can still be recorded in multiple lines. This happens, for instance, when both counterparties are obliged to report, when a central counterparty is involved or when an intermediary is used. Since our focus is on trading activity, in the fifth step, we keep only one observation for each transaction, i.e. we identify duplicates as trades on the same day, in the same security, at the same price, and for the same absolute volume. While the parties involved in the trade are also reported, their reporting style can be inconsistent. We therefore ignore the information on the involved parties to avoid false negative duplicate detections, but instead use it for fine-tuning our filtering parameters. Another crucial variable is the intraday time of the trade. Unfortunately, it is possible that for the same trade, different intraday timestamps are reported, e.g. when one counterparty of an OTC transaction needed additional time to conclude their side of the trade. As a compromise between false positive and false negative duplicate detections, we 
consider two lines to be duplicates only when their intraday time difference is a maximum of ten minutes. By discarding duplicates, we drop another $18.5 \%$ of the initial dataset or $32.8 \%$ of the remaining observations.

Finally, we apply a price filter, through which we first remove trades reported at prices of less than $1 \%$ or more than $500 \%$ of nominal bond value, and then apply a weekly median price filter, filtering out trades that deviate by more than $10 \%$ from the weekly median price. For computational reasons, we do not apply a price reversal filter since we observe that for our subset of actively traded bonds only a negligibly small number of trades would be flagged. Overall, this filtering step drops only $0.4 \%$ of observations. Two additional fields in the dataset indicate whether a deal is on behalf of a client or not and whether the deal affects the balance sheet of the reporting institution. These fields are useful when one is interested in the inventory positions or balance sheets of the reporting institutions.

The cleaning steps described above leave us with about 10.6 million observations, corresponding to single trades, down from an initial 28.4 million observations. Next, we proceed to select our sample of corporate bonds, relying on the CFI code. Thus, in the second column from the right of Panel A in Table 1, we consider only bonds where the 1st, 2nd and 3rd attributes (type of interest, guarantee and redemption) in the CFI code (consolidated from WpHG and CSDB data) are well-defined (i.e. non- "X"). This corresponds to dropping another $8.8 \%$ of trades. From this sample, we select bonds with either a fixed or zero coupon rate and a fixed redemption date, and that are not classified otherwise as hybrid or structured products; we term these as vanilla bonds. Our initial sample of vanilla bonds, therefore, consists of 6.7 million trades in 81,664 bonds with a traded volume of EUR 12.5 trillion.

Panel B of Table 1 distinguishes vanilla bonds by bond securization type, as inferred from the second attribute of the CFI code. The column secured/guaranteed refers to vanilla bonds either secured through assets or guaranteed by a non-government entity (attribute "S" or "G" respectively), Treasury-type bonds are issued or guaranteed by a federal or state government (attribute "T"), e.g. German Bunds and KfW-issued bonds are also part of this category. Unsecured bonds do not carry a guarantee or security (attribute "U"). The largest share of trading volume is due to government bonds with EUR 11.2 trillion, while secured or 
guaranteed bonds make up for EUR 792 billion. Unsecured bonds account for a total trading volume of EUR 438 billion. Based on the CSDB variable "debt_type" we classify unsecured vanilla bonds into corporate bonds and certificates. While there is a large number of 60,817 certificates, they make up only EUR 30 billion of traded volume. The set of corporate bonds is further distinguished in the two rightmost columns into financial bonds (i.e. bonds issued by financial corporations such as banks, insurance corporations and financial auxiliaries) and non-financial bonds (bonds issued by industrial and other non-financial companies). Even though there are only 817 non-financial bonds in our sample, they make up a traded volume of EUR 57 billion, compared to EUR 332 billion traded in 10, 853 financial bonds.

We believe that our sample is highly representative of the German (corporate) bond market, but only to a much lesser extent of the whole European market. Therefore, we focus our attention on German corporate bonds and report the statistics on the number of bonds, the number of trades and traded volume for German-issued bonds in the middle section of Panel B. Throughout this paper, therefore, we will compare the German corporate bond market, based on the BaFin dataset, to the market for U.S. corporate bonds, based on TRACE data. ${ }^{17}$ Therefore, we also provide the corresponding statistics for U.S. bonds at the bottom section of Panel B. It is remarkable that even though the U.S. corporate bond market is much larger overall than the German market in size, we start from an even slightly larger number of bond issues in the latter case. ${ }^{18}$ It is important to stress that our BaFin transaction data for German bonds capture only a share of trading activity (that of German financial institutions, essentially), whereas TRACE data can be considered as covering the whole U.S. corporate bond market. Any comparison we make should therefore be seen with this caveat in mind. We cannot make any final statement on the absolute levels of trading volume and trading activity, which are lower than the total market in the case of our German sample. However, we believe our sample to be representative of the whole market, and hence informative on relative levels of liquidity, trading activity and trading volume. ${ }^{19}$

\footnotetext{
${ }^{17}$ Our data filtering procedure for the TRACE dataset can be found in Appendix A.

${ }^{18}$ Most of these are financial bonds, a finding that is confirmed by industry reports and CSDB. Note that our TRACE sample does not include certificates.

${ }^{19}$ This type of limited sample has been used even when larger datasets are available, as in the U.S. For example, Di Maggio, Kermani, and Song (2017) study trading relationships in the U.S. corporate bond market by using a random sample of TRACE data which covers approximately $10 \%$ of the market, which is likely to
} 


\section{$5 \quad$ Liquidity in Markets with and without Transparency}

In the previous section, we have described, in detail, the filtering and selection process to obtain our final dataset for analysis. In this section, we present our main empirical tests, which can be divided into four parts. First, we provide a general description of the German corporate bond market, focusing on the key characteristics of the assets and their trading activity. Second, we analyze the time-series evolution of liquidity in the German market. Third, we study the determinants of liquidity in the cross-section of the German market with panel regressions on bond characteristics in the spirit of Edwards, Harris, and Piwowar (2007). Fourth, we use a matched-sample approach to compare the transaction costs of similar bonds, at the same point in time, in the German and the U.S. market.

\subsection{Liquidity at the Market Level}

\subsubsection{Full Sample}

In Table 2 we provide summary statistics of bond characteristics and bond-level trading activity, distinguishing between financial and non-financial corporate bonds, and comparing our German BaFin sample with its U.S. TRACE counterpart.

\section{Insert Table 2 here.}

German corporate bonds have, on average, a slightly higher coupon rate (6.3\% compared to $5.9 \%$ for non-financials and $5.4 \%$ compared to $5.2 \%$ for financial bonds), a shorter maturity (5.9 vs. 13.7 and 4.0 vs. 8.5 years for non-financial and financial bonds, respectively) and a smaller issue size (146 million EUR vs. 298 million EUR and 48 million EUR vs. 168 million EUR for non-financial and financial, respectively). ${ }^{20}$ Turning to indicators of trading activity for non-financial bonds, German bonds are, on average, more frequently traded (5.22 vs. 1.23 trades per day and 12.75 vs. 69.48 days between trades). These numbers might be linked to the fact that the German sample has far fewer non-financial bonds than the U.S.

\footnotetext{
be much smaller than our sample.

${ }^{20}$ The numbers relating to the U.S. bonds have been converted into EUR using the average EUR/USD exchange rate over our sample period, which is USD 1.36 per EUR.
} 
one (178 versus 2,374$)$, and hence trading activity is more concentrated. When looking at more similar samples, which is the case for financial bonds $(9,563$ vs. 6,414$)$, the trading activity is higher in the U.S. market. German (U.S.) financial bonds are traded on average 0.18 (0.70) times per day, with an interval of 64.11 (49.62) days between trades. The summary statistics presented so far highlight the heterogeneity across the two markets, especially across financial/non-financial issuers. We will take these factors into consideration when comparing the samples. However, they do not provide a conclusive answer as to which market is more liquid as a whole.

\section{Insert Table 3 here.}

A clearer picture is presented in Table 3, which reports the distribution of bonds in bins of the number of days per year for which we observe trading activity in the bond. First, the number of bonds in the two markets is rather similar: 9,741 in Germany and 8,728 in the U.S. However, when looking at the distribution of the trading frequency, there is a clear difference between the two markets: $32 \%$ of the U.S. sample is traded at least 100 days a year, while only $6 \%$ of the German bonds are traded that often overall. On the other hand, $48 \%$ of the U.S. sample is rarely traded (0-50 trading days a year). The group of rarely traded bonds in the German sample amounts to $87 \%$, representing the great majority of the market. This major difference is a clear indication of greater market liquidity in the U.S., with a significantly larger number of securities that trade often. This is an indication of the U.S. market being likely to provide more informative prices. Looking at the average turnover of bonds across our sample gives a similar picture: German bonds have a lower turnover than those in the U.S., both for non-financial (133\% vs. $171 \%$ ) and financial issuers (29.76\% vs. $0.62 \%) .{ }^{21}$ Our results are consistent with various theoretical studies showing that transparency lowers costs for unsophisticated investors and, therefore, incentivizes participation in the market. ${ }^{22}$

\footnotetext{
${ }^{21}$ These numbers are obtained as the ratio of the average amount issued to the average total volume traded in Table 2.

${ }^{22}$ See, for example, Pagano and Roell (1996), Duffie, Dworczac, and Zhu (2017).
} 


\subsubsection{Frequently Traded Bonds}

After analyzing the market as a whole, we move to the cross-section of bonds and aim to provide a precise estimate of transaction costs at the asset level. We concentrate on a set of bonds for which liquidity measures can be estimated. In line with the best practices established in the literature, we consider only bond-week observations that have at least 8 transactions. $^{23}$ This leaves us with 1,703 German bonds (118 non-financial and 1,585 financial bonds) and 6, 493 U.S. bonds (1,744 non-financial and 4,749 financial bonds). Table 4 provides the descriptive statistics of bond characteristics and trading activity for this liquid sample.

\section{Insert Table 4 here.}

The sub-sample partially confirms the characteristics that we observe in the larger one. As for the whole market, the amount issued is smaller for German corporate bonds. Among nonfinancial bonds, the average number of trades per day is larger for German bonds compared to the U.S., whereas among financials, the distributions are quite similar. For all these measures, the dispersion is quite large, indicating that both samples feature significant cross-sectional heterogeneity. For both non-financials and financials, coupon rates are largely similar, while the maturity is shorter for German bonds. ${ }^{24}$

In an attempt to provide a comprehensive description of the liquid sample, Table 5 displays information on its credit ratings. ${ }^{25}$ A large fraction of the assets in the sample is rated investment grade, especially among German financial bonds. Interestingly, there is a lack of credit ratings data among German non-financial bonds, where there is rating information only for 28 out of the 118 bonds. The low proportion of rated non-financial bonds can be explained by the credit market structure in Europe, which not only relies heavily on bank loan

\footnotetext{
${ }^{23}$ Estimations based on TRACE data are usually performed at a daily frequency. However, given the less complete coverage of trading in German bonds, this would impose too strict a selection criterion on the German sample. Nevertheless, while we use a weekly frequency for our analysis, robustness checks at a daily frequency show that those results are in line with our findings below.

${ }^{24}$ Figure I1 in the Internet Appendix also reports the monthly traded volume in liquid corporate bonds for both our German and U.S. samples.

${ }^{25}$ Credit ratings for the German BaFin sample were obtained from Bloomberg, Thomson Reuters and Bundesbank databases, whereas ratings for the TRACE sample are from Mergent FISD.
} 
financing, but also involves corporate bonds that are often held until maturity by long-term investors such as insurance companies. As a consequence, many European corporate bond issuers do not seek for a credit rating, unlike their U.S. counterparts.

\section{Insert Table 5 here.}

\subsection{Liquidity at the Asset Level}

\subsubsection{Measuring Transaction Costs}

In order to estimate asset-specific transaction costs, we employ a range of liquidity metrics that have been tested and verified on U.S. TRACE data. The Amihud measure, proposed in Amihud (2002), is a proxy for market price impact, i.e. the average price shift induced by a trade. The other measures we use capture the cost of a round-trip trade: price dispersion, the Roll measure, the imputed round-trip cost and the effective bid-ask spread all estimate the loss associated with buying and immediately selling an asset. All details regarding the calculation of the measures are provided in Appendix B. It is important to highlight two aspects of our methodology. First, while these measures are typically calculated on a daily basis for U.S. TRACE data, here we use a weekly frequency due to the low trading frequency of the German market to ensure comparability. In this way, we can include a larger number of German bonds in our tests and provide a more comprehensive picture on the trading costs. Second, the calculation of the effective bid-ask spread requires the trade sign, i.e. whether a trade was buyer- or seller-initiated. This information is provided in TRACE but not in our BaFin data on the German market. We therefore infer the trade sign in the German case using the algorithm of Lee and Ready (1991) by comparing our trade prices with quotes from Bloomberg. Since such quotes are not available for all bonds in our sample, this effectively creates a different subsample and we need to be careful when comparing the effective bid-ask spread with other liquidity measures of German bonds. Such a discrepancy is displayed in Figure 1, where we plot the number of bonds for which the liquidity metrics of price dispersion and the effective bid-ask spread could be computed in each week of our sample. ${ }^{26}$ The number

\footnotetext{
${ }^{26}$ The criteria for the calculation of price dispersion are almost identical to those of the Amihud and Roll measures as well as the imputed round-trip cost. In the interest of clarity, we only show the line corresponding
} 
of bonds for which we compute the effective bid-ask spread is therefore always smaller than that for the other liquidity metrics because of the reasons mentioned above.

\section{Insert Figure 1 here.}

Table 6 provides summary statistics for the different liquidity measures. Panel A reports information for both German and U.S. non-financial bonds. There is large cross-sectional variation among the liquidity measures in both markets. The price dispersion and Roll measures, and the effective bid-ask spread based on our BaFin sample, are, on average, lower for German non-financial bonds than the corresponding U.S. bonds in TRACE, whereas the Amihud illiquidity measure and the round trip cost are higher. On the other hand, in Panel B, the U.S. financial bonds in TRACE are shown to be, on average, always more illiquid than German financial bonds in the BaFin sample. However, we hasten to emphasize that a simple average comparison is misleading. Such a comparison should not induce us to conclude that German corporate bonds are generally more liquid than the U.S. corporate bonds. In fact, U.S. financial bonds in TRACE appear to be more illiquid because of the large differences in the number of bonds considered in both samples, i.e. the number of bond-week observations in the BaFin German sample is only as much as one-eighth of the TRACE U.S. sample in Panel A, whereas in Panel B, this ratio is even less than 10 percent. The time-series dynamics of these measures are potentially different and will be taken into account in the analysis below. In the following subsections, we perform a finer, more granular analysis of the different liquidity measures from a time-series and cross-sectional perspective, and try to investigate potential similarities and differences in the patterns and cross-sectional characteristics of the different liquidity measures between U.S. and German corporate bonds.

\section{Insert Table 6 here.}

to price dispersion in the figure, while the other measures behave in a similar manner. 


\subsubsection{Time Series Dynamics of Transaction Costs}

In describing the evolution of liquidity over time, we first consider the effective bid-ask spread. This is the liquidity measure that relies on the most complete set of information and, thus, is our benchmark for the other measures. Recall that the only caveat with the effective bid-ask spread is that it requires the information on the initator of the trade, which is only available for a smaller sample of German bonds that have quote information. Figure 2 shows the average level of the effective bid-ask spread in German (U.S.) bonds in Panel (a) (Panel (b)), separated for financial and non-financial bonds. For both countries, there is a sharp increase in illiquidity, associated with the financial crisis at the end of 2008. Liquidity in U.S. bonds has since improved steadily, and the average level of the effective bid-ask spread was below 100 basis points. Financial bonds were, on average, less liquid through 2012, a gap that has closed in 2013 and 2014. We observe similar dynamics for German financial bonds, whereas German non-financials seem to become more illiquid from 2013 on.

Again, we cannot distinguish between the two markets by simply looking at the dynamics of the effective bid-ask spread to ascertain whether this is due to the changing composition of our sample towards more bonds of smaller issue size (which is typically associated with lower liquidity), or due to a general deterioration of market liquidity. From Figure 1 we know that the number of liquid German bonds changed significantly in the last part of the period and, instead, the amount outstanding did not increase significantly. From Figure 2, it also appears that during the first part of our sample period, German corporate bonds were actually more liquid than their U.S. counterparts. It should be borne in mind, however, that the limited sample for which we compute the effective bid-ask spread is likely to be biased towards more liquid bonds. In that case, the clear differences between the two markets in terms of the distribution of the number of trades per bond in the sample highlighted in Table 3 prevent us from comparing the patterns of these figures in Panels (a) and (b).

\section{Insert Figure 2 here.}

For the same reason that the effective bid-ask spread is based on a smaller sample of bonds, it can result in a rather noisy liquidity measure, as suggested by the spikes (especially 
for financial bonds) in Panel (a) of Figure 2. Importantly, we find these observed trends to be robust in the other liquidity measures, for which we do not have the trade initiation limitation and, thus, can use the full sample of liquid bonds. Panels (a) to (d) of Figure 3 show the timeseries dynamics of the price dispersion, Roll, imputed round-trip cost and Amihud measures respectively for German bonds, and for their counterparts in Figure 4 for U.S. bonds. The dynamics of these measures for U.S. bonds coincide with those for the effective bid-ask spread, whereas the dynamics of liquidity in the German market require more detailed attention.

\section{Insert Figures 3 and 4 here.}

For German corporate bonds, we first note that the qualitative patterns that emerge from the single panels of Figure 3 are quite different from one another. Price dispersion and imputed round-trip cost behave in a similar manner to the effective bid-ask spread, but several features of the Roll and Amihud measures are not replicated in the other liquidity metrics. Keeping in mind that the Roll measure is based on the auto-covariance of returns, and the Amihud measure on average returns during an observation period, both measures ultimately rely on the pattern of bond returns. The divergence between these two measures may be mostly because not all time stamps and prices are observed in the dataset and, hence, returns are not properly defined. We therefore focus our attention on the effective bid-ask spread, price dispersion, imputed round-trip cost and, to some extent, the Amihud measure. ${ }^{27}$

We now look at the evolution of liquidity in the German sample and compare it to the U.S. market. A common feature of these time series is the sudden increase in illiquidity at the end of 2008 due to the financial crisis, characterized by a sharp spike at the end of 2008, in conjunction with the Lehman Brothers bankruptcy event. The impact of the European sovereign debt crisis of 2012 is also evident in the graphs corresponding to German bonds, whereas this effect is of minor consequence for U.S. bonds. All our measures, with the exception of the Roll measure, show a divergence of German non-financial bonds, which became more illiquid than German financial bonds. As suggested above, the figures we present

\footnotetext{
${ }^{27}$ We report correlation coefficients for the liquidity measures in Table I 2 in the Internet Appendix. The results are in line with our more descriptive findings above.
} 
in this section allow for at least two alternative explanations. First, corporate bonds may have become more illiquid (and also more numerous) in general. Second, trading activity may have expanded to newly issued bonds, many of which are more illiquid, and thus, while the liquidity of individual bonds may not have changed, the overall liquidity level might be lower, since our sample over time gradually includes more illiquid securities. We aim to distinguish better between these two effects in our panel regressions below, since no such trend is observed for U.S. corporate bonds.

\subsubsection{Determinants of Transaction Costs in the Cross-Section}

In this subsection, we perform a panel analysis that allows us to investigate whether the liquidity measures for German bonds are related to certain bond characteristics, and whether the sensitivity of these measures with respect to these characteristics is of similar magnitude and statistical significance for the U.S. and German samples. The results of the panel analysis are reported in Table 7 .

\section{Insert Table 7 here.}

Table 7 shows that, for German corporate bonds, the amount issued is not an important determinant for the various liquidity measures, the only exception being the effective bid-ask spread, which shows a negative and statistically significant coefficient. In contrast, for the U.S. corporate bond market, this is a highly significant variable for almost all the various liquidity measures. A potential explanation for this divergence between the two markets is the relatively lower dispersion in the amounts outstanding in the case of German corporate bonds in our sample, in particular due to the absence of bonds with very large amounts outstanding.

A bond's credit rating is also relevant for its liquidity, i.e. with more risky bonds being less liquid, since for three out of five liquidity measures, this variable is statistically different from zero at the $1 \%$ level. For the U.S., all the liquidity measures are sensitive to the credit rating variable, with the respective coefficients being statistically significant. However, if we compare the sizes of the coefficients between the two panel regressions, we observe that each 
additional change of one notch in the credit rating is associated with a larger reduction of liquidity, which could be due to a sample selection bias: As we show in Table 5, the U.S. corporate bond sample contains a larger fraction of non-investment grade bonds than its German counterpart.

The time to maturity variable is highly significant and positive for both German and U.S. corporate bonds, with a similar magnitude of sensitivity, for most of the liquidity measures. The only exception to this is the Amihud measure for the German sample. The age variable is slightly significant for almost all the liquidity measures for the German corporate bonds, but is significant only for the Amihud and the effective bid-ask spread measures for the U.S. sample. The traded volume of the bond in a given week is associated with an improvement in the liquidity of these bonds, but this variable is only marginally significant both for the German and the U.S. sample. The dummy variable for financial bonds is highly significant for both the German and the U.S. sample, indicating that financial bonds are, on average, more illiquid than non-financial bonds. A comparison of the coefficients for the financial dummy between the two samples indicates that the reduction in liquidity is larger, on average, for U.S. financial bonds than for the German bonds.

The panel analysis also allows us to investigate whether liquidity in general has improved in recent years. Recent literature has looked at this important question on how market liquidity has changed after the global financial crisis. There is a strand of the literature that claims that alternative measures of liquidity did not worsen after the crisis (Trebbi and Xiao, 2017; Adrian, Fleming, Shachar, and Vogt, 2017; Anderson and Stulz, 2017). The findings of these papers seem puzzling, especially given that the large financial dealers are less active in cash bond (Choi and Huh, 2018), and derivatives markets (Feldhütter, GehdeTrapp, and Gündüz, 2017) due to regulatory constraints and their own risk-bearing capacity (Bessembinder, Jacobsen, Maxwell, and Venkataraman, 2018; Bao, O'Hara, and Zhou, 2018). In fact, the recent literature has distinguished a shift in liquidity provision from major dealers to asset manager and end-users. Building upon this literature, our usage of market-wide measures of liquidity allows us to compare the aggregate provision of liquidity across the European and U.S. cash bond markets. 
We investigate how liquidity in general has changed over time by including a dummy variable for each year of our sample, with the base year being 2014. The dummies from 2008 until 2012 are generally positive and statistically different from zero in three out of five liquidity measures. Transaction costs in 2013 do not show a difference relative to those in 2014. Our results indicate that, for three out of five measures, liquidity improved after controlling for the change in sample composition of bond characteristics. The same applies for the U.S. where, in this case, the variable is positive and significant for all five liquidity measures, in line with the finding of Adrian, Fleming, Shachar, and Vogt (2017). Generally, the time dummies confirm the patterns observed in Figures 2 through 4.

Overall, our results are in line with traditional search theories in OTC markets. Market liquidity is greater for corporate bonds that have larger amounts outstanding, are better rated, have a shorter time to maturity, a younger age, and trade in larger volumes. Large assets are easier to find, and are therefore cheaper to trade. A similar argument applies for the credit rating and the time to maturity: when a bond has a better rating (shorter maturity), dealers will require a lower spread, since it is less risky for them to hold it in their inventory. Trades with larger volumes are most likely being employed by larger and more sophisticated investors, who bear lower search costs, have greater bargaining power, and trade with lower

spreads, in equilibrium. It is worth mentioning that these characteristics drive the liquidity less strongly in the German sample than in the U.S. sample. This is especially true for bond size and volume. This is, at least partially, due to the smaller size of the German sample, and also its lower cross-sectional variation in bond characteristics, compared to the U.S. sample.

\subsubsection{Are Transparent Markets more Liquid for all Corporate Bonds? A Matched Sample Analysis}

Our analysis thus far has pointed to the conclusion that the U.S. corporate bond market is far more liquid than its German counterpart. First, the fraction of U.S. bonds that are traded frequently is larger than for German bonds. Second, the average bond in the U.S. market has significantly larger turnover than the average bond in Germany. However, those results are derived from a comparison of the two markets on an aggregate dimension, yielding little 
insight into what happens at the security level. Several theoretical studies have pointed to the possibility that some securities may even have lower transaction costs in opaque markets than in transparent ones. ${ }^{28}$ In light of these prior findings, it is interesting to assess whether such theoretical predictions can also be observed empirically. Hence, in this section, we shift our attention to a comparison between transaction costs at the security level.

We employ a matched-sample approach, where the transaction costs of bonds with the same characteristics, at the same point in time, are compared. As pointed out in Section 5.1.2, the estimation of transaction costs is possible only for bonds that trade sufficiently frequently. Therefore, we are effectively comparing the most liquid segment of the German corporate bond market with similar securities in the U.S. market at the same point in time. The matched sample approach allows us to compare exactly the same number of bonds across the two markets. In order to rule out variations in liquidity over time as a source of differences, our matching of bonds is performed on a weekly basis. In other words, for each week, we consider the set of German bonds for which we are able to compute liquidity measures as our treatment sample and construct a control sample of U.S. bonds using "nearest neighbor" matching. The variables used in the matching procedure are the amount outstanding (in USD), the coupon rate, the credit rating notch, the age, the maturity at issuance, and the average trading volume. We match only financial (non-financial) bonds to financial (nonfinancial) bonds and impose minimum closeness criteria for a matched pair to be part of our sample. ${ }^{29}$ In order to minimize the impact of any remaining sample differences, we then repeat the analysis of Table 7 for the matched sample with two slight modifications. First, we include a dummy variable that is one for German bonds (our treatment group) and zero for U.S. bonds (control group). Second, we drop regression variables that are related to the sample coverage. ${ }^{30}$

\footnotetext{
${ }^{28}$ See Naik, Neuberger, and Viswanathan (1999), Bloomfield and O'Hara (1999), Holmstrom (2015), Bhattacharya (2016).

${ }^{29}$ We only keep matches within less than half a standard deviation of the distance measure from the original observation. Our results are robust to variations in the matching approach, such as the variable set for matching, matching with or without replacement, matching to a larger control set and other thresholds for closeness.

${ }^{30}$ Otherwise, we would introduce a bias from the more complete coverage of our U.S. sample against the partial coverage of trading activity in German bonds in our dataset. In practice, this amounts to dropping the variable "volume".
} 


\section{Insert Table 8 here.}

Table 8 shows the results of the matched panel regression. The drivers of liquidity are consistent with the findings from the previous sections: larger and better-rated bonds are more liquid, as are non-financial bonds. Illiquidity increases with both age and time to maturity, i.e. bonds with shorter maturities and bonds that have been issued recently are more liquid. Most strikingly, the coefficient for German bonds is negative for all liquidity measures, and significantly so, for all but the imputed round-trip cost. This implies that liquid German bonds are actually 39 to 61 basis points more liquid than comparable U.S. bonds even after controlling for bond and time effects.

It is worth identifying possible reasons for this finding, which is most likely related to our focus on the most frequently traded German bonds. As argued earlier in the light of the theoretical literature, a potential explanation for our finding is that, when there is little transparency, investors concentrate their demand on a few well-traded assets, resulting in "crowding." As a consequence, the liquidity of these few bonds is particularly high, while the others are barely traded, resulting in a greater dispersion of liquidity across bonds. On the other hand, when overall transparency increases, investors spread their portfolios across a wider range of assets, given the greater level of information available. While the overall market liquidity improves, there is relatively less demand for the previously "well-traded assets," and hence their transaction costs could be higher in some cases.

\section{Conclusion}

In this paper, we study the impact of transparency on liquidity in OTC markets, the subject of an important debate for academia, industry and regulators. Supporters of OTC market transparency argue that it reduces the asymmetry of information between dealers and investors, and therefore encourages the participation of retail/uninformed investors. On the other hand, OTC market transparency could increase transaction costs for investors by eliminating dealers' information rents and, thus, their incentives to compete, or even participate in the market. We contribute to this debate by providing an analysis of liquidity in a corpo- 
rate bond market without trade transparency (Germany), and comparing our findings to the results in a market with full disclosure (the U.S.), employing a unique regulatory dataset of transactions of German financial institutions from 2008 until 2014 along with a widely used database for U.S. corporate bonds.

We find that overall, observed trading activity is much lower in the German market. The bonds that trade at least 8 times per week are only $17 \%$ of our sample, as against $74 \%$ of the traded sample in the U.S. universe. Looking at the market as a whole, overall liquidity is clearly much higher in the U.S., with a significantly larger number of securities that trade often. Our time-series analysis shows that the average transaction costs for German corporate bonds spiked sharply during the 2008-2009 global financial crisis, but less so during the 20102012 sovereign debt crisis. The cross-sectional regressions confirm that, similar to the U.S., the determinants of German corporate bond liquidity are in line with search theories of OTC markets. In other words, a bond is more liquid if it has a larger issue size, a better rating, a shorter time to maturity, a younger age, and a larger volume traded. Our matchedsample analysis reveals that frequently traded German bonds have lower transaction costs than comparable bonds in the U.S. market.

Our results are of considerable interest to market participants, on both the buy and sell side as well as to regulators. Furthermore, our findings provide a benchmark for future research on the measurement of liquidity in European fixed-income markets, which could benefit from a more detailed, research-oriented data. In fact, from January 2018, MiFID II requires all firms in the European Union to publish details of their OTC transactions in non-equity instruments almost in real time (commonly referred to as OTC post-trade transparency). Hence, the introduction of MiFID II is likely to change the landscape of the European fixed-income market with new regulations on the provision of trading services and reporting. Indeed, there are significant concerns in the financial services industry about the cost of fulfilling these requirements, especially since mandatory transparency could potentially hamper liquidity due to the withdrawal of dealers who would be concerned about "showing their hand". Our results imply that the pre-MiFID opaque structure could be one of the reasons why a selected set of German bonds are revealed to be more liquid than their U.S. 
counterparts.

Although our study provides some insights into a market that has so far been dark for many of its market participants, from an academic point of view, and even from a regulatory perspective, much still remains to be done to address specific policy questions. This said, our findings lay the foundations for a future academic and regulatory research agenda. Without data regarding market liquidity before the implementation of MiFID II along the lines of our findings, it would be impossible to assess empirically whether pre- and post-trade transparency in the European bond market indeed improved liquidity. While the scope and mandate of MiFID II are vast, it remains to be seen how well and how broadly the directive will be implemented. Suffice it to say that even in the U.S., the implementation of TRACE took place over several years just for the corporate bond market, and its extension to other fixedincome markets is still work in progress. It is fair to assume that the dissemination of a reasonable sample of such data will take several years. Our analysis on liquidity has shown, for instance, that given the low number of bonds traded at significant frequency, any increase in the number of these liquid bonds due to MiFID II regulation would be an achievement. Once reliable data from MiFID II become available in the future, our study could serve as a benchmark of the "before" period. As the construction of reliable transaction databases will be a challenge in the years to come, we expect our findings to remain valid and relevant in the interim.

Another issue that can be addressed based on our evidence is how the Corporate Sector Purchase Programme (CSPP), launched by the ECB in June 2016 as part of its Quantitative Easing $(\mathrm{QE})$, has reshaped the liquidity in the European corporate bond markets. This paper could be the basis for a proper analysis of the impact of corporate bond purchases in the CSPP. Our paper would provide such a benchmark to assess the impact of this specific ECB program, which does not have a counterpart in the QE programs of the U.S. Federal Reserve System (FED). Overall, our paper serves the purpose of shedding light on what was previously unknown and of opening up an important topic for further discussion. 


\section{References}

Adrian, Tobias, Michael Fleming, Or Shachar, and Erik Vogt, 2017, Market liquidity after the financial crisis, Annual Review of Financial Economics 9, 43-83.

Amihud, Yakov, 2002, Illiquidity and stock returns: Cross-section and time series effects, Journal of Financial Markets 5, 31-56.

Anderson, Mike, and René M. Stulz, 2017, Is post-crisis bond liquidity lower?, NBER Working Paper No. $2331 \%$.

Aquilina, Matteo, and Felix Suntheim, 2017, Liquidity in the UK corporate bond market: evidence from trade data, Journal of Trading 12, 67-80.

Asriyan, Vladimir, William Fuchs, and Brett Green, 2017, Information spillovers in asset markets with correlated values, American Economic Review 107, 579-611.

Aussenegg, Wolfgang, Lukas Goetz, and Ranko Jelic, 2015, Common factors in the performance of European corporate bonds - Evidence before and after the financial crisis, European Financial Management 21, 265-308.

Autorité des Marchés Financiers, 2015, Study of liquidity in French bond markets, Report by Autorité des Marchés Financiers.

Bank for International Settlements, 2016, Electronic trading in fixed income markets, Bank for International Settlements Report.

Bao, Jack, Maureen O'Hara, and Xing (Alex) Zhou, 2018, The Volcker Rule and marketmaking in times of stress, Journal of Financial Economics 130, 95-113.

Bao, Jack, Jun Pan, and Jiang Wang, 2011, The Illiquidity of corporate bonds, Journal of Finance 66, 911-946.

Bessembinder, Hendrik, Stacey E. Jacobsen, William F. Maxwell, and Kumar Venkataraman, 2018, Capital commitment and illiquidity in corporate bonds, Journal of Finance 73, 16151661.

Bessembinder, Hendrik, William F. Maxwell, and Kumar Venkataraman, 2006, Market transparency, liquidity externalities, and institutional trading costs in corporate bonds, Journal of Financial Economics 82, 251-288.

Bhattacharya, Ayan, 2016, Can transparency hurt investors in over-the-counter markets?, Available at SSRN No. 2746910.

Biais, Bruno, Fany Declerck, James Dow, Richard Portes, and Ernst-Ludwig von Thadden, 2006, European corporate bond markets: Transparency, liquidity, efficiency, CEPR Research Report available at http://www.cepr.org/PRESS/TT_CorporateFULL.pdf.

Bloomfield, Robert, and Maureene O'Hara, 1999, Market transparency: Who wins and who loses?, Review of Financial Studies 12, 5-35. 
Boortz, Christopher, Stephanie Kremer, Simon Jurkatis, and Dieter Nautz, 2014, Information risk, market stress and institutional herding in financial markets: New evidence through the lens of a simulated model, SFB 649 Discussion Paper No. 2014-029.

Castagnetti, Carolina, and Eduardo Rossi, 2013, Euro corporate bond risk factors, Journal of Applied Econometrics 28, 372-391.

Choi, Jaewon, and Yesol Huh, 2018, Customer liquidity provision: Implications for corporate bond transaction costs, Available at SSRN No. 2848344.

Deutsche Bundesbank, 2017, The market for corporate bonds in the low-interest-rate environment, Deutsche Bundesbank Monthly Report July 2017 pp. 17-32.

Di Maggio, Marco, Amir Kermani, and Zhaogang Song, 2017, The value of trading relationships in turbulent times, Journal of Financial Economics 124, 266-284.

Díaz, Antonio, and Eliseo Navarro, 2002, Yield spread and term to maturity: Default vs. liquidity, European Financial Management 8, 449-477.

Dick-Nielsen, Jens, 2009, Liquidity biases in TRACE, Journal of Fixed Income 19, 43-55.

Dick-Nielsen, Jens, Peter Feldhütter, and David Lando, 2012, Corporate bond liquidity before and after the onset of the subprime crisis, Journal of Financial Economics 103, 471-492.

Duffie, Darrell, 2012a, Dark markets: Asset pricing and information transmission in overthe-counter markets. (Princeton University Press).

Duffie, Darrell, 2012b, Market making under the proposed Volcker Rule, Rock Center for Corporate Governance at Stanford University Working Paper No. 106.

Duffie, Darrell, Piotr Dworczac, and Haoxiang Zhu, 2017, Benchmarks in search markets, Journal of Finance 72, 1983-2044.

Edwards, Amy K., Lawrence E. Harris, and Michael S. Piwowar, 2007, Corporate bond market transaction costs and transparency, Journal of Finance 62, 1421-1451.

European Securities and Markets Authority, 2016, EU corporate bond market liquidity Recent evidence, ESMA Report on Trends, Risks and Vulnerabilities No. 2/2016.

Feldhütter, Peter, 2011, The Same bond at different prices: Identifying search frictions and selling pressures, Review of Financial Studies 25, 1155-1206.

Feldhütter, Peter, Monika Gehde-Trapp, and Yalin Gündüz, 2017, Who provides liquidity in the credit default swap market?, Working Paper.

Fermanian, Jean-David, Olivier Guéant, and Jiang Pu, 2016, The behavior of dealers and clients on the European corporate bond market: The Case of multi-dealer-to-client platforms, Market Microstructure and Liquidity Vol. 2, Nos. 3844, 1750004.

Friewald, Nils, Rainer Jankowitsch, and Marti G. Subrahmanyam, 2012, Illiquidity or credit deterioration: A study of liquidity in the U.S. corporate bond market during financial crises, Journal of Financial Economics 105, 18-36. 
Friewald, Nils, Rainer Jankowitsch, and Marti G. Subrahmanyam, 2017, Transparency and liquidity in the structured product market, Review of Asset Pricing Studies 7, 316-348.

Frühwirth, Manfred, Paul Schneider, and Leopold Sögner, 2010, The Risk microstructure of corporate bonds: A case study from the German corporate bond market, European Financial Management 16, 658-685.

Greenwich Associates, 2014, Greenwich Associates European fixed-income investors study, Industry Report.

Harris, Lawrence E., and Michael S. Piwowar, 2006, Secondary trading costs in the municipal bond market, Journal of Finance 61, 1361-1397.

Holmstrom, Bengt, 2015, Understanding the role of debt in the financial system, BIS Working Paper No. 479

Hong, Gwangheon, and Arthur Warga, 2000, An empirical study of bond market transactions, Financial Analysts Journal 56, 32-46.

Houweling, Patrick, Albert Mentink, and Ton Vorst, 2005, Comparing possible proxies of corporate bond liquidity, Journal of Banking \&S Finance 29, 1331-1358.

Jankowitsch, Rainer, Florian Nagler, and Marti G. Subrahmanyam, 2014, The determinants of recovery rates in the U.S. corporate bond market, Journal of Financial Economics 114, $155-177$.

Jankowitsch, Rainer, Amrut Nashikkar, and Marti G. Subrahmanyam, 2011, Price dispersion in OTC markets: A new measure of liquidity, Journal of Banking $\mathscr{G}$ Finance 35, 343-357.

Klein, Christian, and Christoph Stellner, 2014, The Systematic risk of corporate bonds: Default risk, term risk, and index choice, Financial Markets and Portfolio Management 28, $29-61$.

Kremer, Stephanie, and Dieter Nautz, 2013a, Causes and consequences of short-term institutional herding, Journal of Banking ES Finance 37, 1676-1686.

Kremer, Stephanie, and Dieter Nautz, 2013b, Short-term herding of institutional traders: New evidence from the German stock market, European Financial Management 19, 730-746.

Lee, Charles, and Mark J. Ready, 1991, Inferring trade direction from intraday data, Journal of Finance 46, 733-746.

Lin, Hai, Junbo Wang, and Chunchi Wu, 2011, Liquidity risk and expected corporate bond returns, Journal of Financial Economics 99, 628-650.

Linciano, Nadia, Francesco Fancello, Monica Gentile, and Matteo Modena, 2014, The liquidity of dual-listed corporate bonds - Empirical evidence from Italian markets, CONSOB Working Paper No. 79.

Naik, Narayan, Andreas Neuberger, and S. Viswanathan, 1999, Trade disclosure regulation in markets with negotiated trades, Review of Financial Studies 12, 873-900. 
Pagano, Marco, and Ailsa Roell, 1996, Transparency and liquidity: A comparison of auction and dealer markets with informed trading, Journal of Finance 51, 579-611.

Pagano, Marco, and Ernst-Ludwig Von Thadden, 2004, The European bond markets under EMU, Oxford Review of Economic Policy 20, 531-554.

Roll, Richard, 1984, A simple implicit measure of the effective bid-ask spread in an efficient market, Journal of Finance 39, 1127-1139.

Schestag, Raphael, Philipp Schuster, and Marliese Uhrig-Homburg, 2016, Measuring liquidity in bond markets, Review of Financial Studies 29, 1170-1219.

Todorov, Karamfil, 2017, Quantify the Quantitative Easing: Impact on bond liquidity and corporate debt issuance, Available at SSRN No. 3139875.

Trebbi, Francesco, and Kairong Xiao, 2017, Regulation and market liquidity, Management Science forthcoming.

Utz, Sebastian, Martina Weber, and Maximilian Wimmer, 2016, German Mittelstand bonds: Yield spreads and liquidity, Journal of Business Economics 86, 103-129.

Van Landschoot, Astrid, 2008, Determinants of yield spread dynamics: Euro versus U.S. dollar corporate bonds, Journal of Banking $\&$ Finance 32, 2597-2605. 


\section{A TRACE data preparation}

We use two main sources of data for our analysis of the U.S. corporate bond market. We obtain information on bond characteristics from Mergent FISD, while the TRACE Enhanced database contains bond transactions' prices, which are used for the calculation of the liquidity measures. ${ }^{31}$ For comparability with the BaFin data, our sample spans January 2008 to December 2014. For TRACE, we follow standard data cleaning procedures described by Dick-Nielsen (2009). ${ }^{32}$ Furthermore, we implement the price filters used in Edwards, Harris, and Piwowar (2007), and Friewald, Jankowitsch, and Subrahmanyam (2012). ${ }^{33}$ We consider only straight (simple callable and puttable) bonds, and exclude any bond with complex structures or optionalities. Details on the number of observations lost in the cleaning process can be found in Table I1 of the Internet Appendix. In defining our baseline sample of vanilla bonds, secured bonds are identified as those with SECURITY_TYPE= "SS" in Mergent FISD. Treasury-type bonds are those with bond type among "USBD", "USBL", "USBN", "USNT", "USSI", "USSP", "USTC" in Mergent FISD. Unsecured bonds are the remaining ones that do not fall into any of the previous two categories. To divide unsecured bonds into those issued by non-financial firms and those issued by financial corporations, we use the industry classification provided by Mergent FISD. Financial bonds are those with INDUSTRY_GROUP=2, while non-financial bonds are those belonging to any other industry group code.

\section{B Liquidity measures}

We employ a set of liquidity measures that mostly capture the costs associated with price-impact and round-trip trades, following the presentation in Friewald, Jankowitsch, and Subrahmanyam (2017). While these measures are typically calculated on a daily basis for

\footnotetext{
${ }^{31}$ In addition to the TRACE standard version, TRACE Enhanced includes buy-sell indicators for each transaction, and the trading volume is not capped.

${ }^{32}$ We delete duplicates, trade corrections, and trade cancellations on the same day. Moreover, we delete reversals, which are errors detected on a day after they occurred.

${ }^{33}$ We adopt a median and a reversal filter. The median filter eliminates any transaction where the price deviates by more than $10 \%$ from the daily median or from a nine-trading-day median, which is centered at the trading day. The reversal filter eliminates any transaction with an absolute price change that deviates at the same time by at least $10 \%$ from the price of the transaction before, the transaction after, and the average of the two.
} 
U.S. TRACE data, all measures calculated here are based on weekly data. This allows us to include more bonds in our analysis that are relatively actively traded, but not typically on a daily basis. We define our notation such that $L i q_{t}^{i}$ is the liquidity of bond $i$ in week $t$ and $N_{t}^{i}$ is the number of trades in bond $i$ in week $t$.

- The Amihud measure, proposed in Amihud (2002), is our proxy for price impact. The more a trade of a given size shifts the observed price, the higher the Amihud measure and the less liquid the bond. The measure is obtained as the mean ratio of absolute log returns to trade volumes:

$$
\operatorname{Amihud}_{t}^{i}=\frac{1}{N_{t}^{i}} \sum_{j=1}^{N_{t}^{i}} \frac{\left|r_{t}^{i, j}\right|}{V_{t}^{i, j}}
$$

where the index $j$ spans all trades in bond $i$ in week $t$ while $r_{t}^{i, j}$ and $V_{t}^{i, j}$ are the $(\log )$ return and transaction volume associated with the trade $j$. The measure is given in units of basis points per million EUR (per million USD for our TRACE sample), and we require at least eight transactions per week in order to calculate it.

All the other following measures capture the liquidity component that is associated with the cost of a round-trip trade and are given in units of basis points:

- Price dispersion was introduced by Jankowitsch, Nashikkar, and Subrahmanyam (2011). The idea is that the lower the volatility of prices around the consensus price, the more liquid is the bond, since agents are more likely to trade the bond at its fair value. It is calculated as the root mean squared (weighted) difference between traded prices $P_{t}^{i, j}$ and the market valuation $P_{t}^{i}$ proxied by the volume-weighted average trade price.

$$
\text { PriceDisp } p_{t}^{i}=\sqrt{\frac{1}{\sum_{j=1}^{N_{t}^{i}} V_{t}^{i, j}} \sum_{j=1}^{N_{t}^{i}}\left(P_{t}^{i, j}-P_{t}^{i}\right)^{2} V_{t}^{i, j}}
$$

with $P_{t}^{i}=\frac{1}{\sum_{j=1}^{N_{t}^{i}} V_{t}^{i, j}} \sum_{j=1}^{N_{t}^{i}} P_{t}^{i, j}$ As for the Amihud measure, we require a minimum of eight transactions per week.

- Roll is the Roll measure that relates the autocorrelation of returns to the bid-ask spread, 
developed in Roll (1984). It is obtained as twice the square root of the negative autocovariance of returns.

$$
\operatorname{Roll}_{t}^{i}=2 \sqrt{-\operatorname{Cov}\left(r_{t}^{i, j}, r_{t}^{i, j-1}\right)}
$$

We require a minimum of eight transactions per week in order to compute the Roll measure.

- Imputed round-trip cost, developed in Feldhütter (2011) and applied to OTC markets in Dick-Nielsen, Feldhütter, and Lando (2012), proxies the bid-ask spread by comparing the highest to the lowest price of a set of transactions with identical volumes. These transactions are assumed to belong to a round-trip trade and the highest (lowest) of their prices thus to correspond to the prevailing ask (bid) price:

$$
\text { ImputedRTCost } t_{t}^{i}=\frac{1}{B_{t}^{i}} \sum_{b=1}^{B_{t}^{i}} 1-\frac{\min P_{t}^{i, b}}{\max P_{t}^{i, b}}
$$

where $B_{t}^{i}$ is the number of sets with trades of identical size and $P_{t}^{i, b}$ is the set of prices that belong to the set $b$. We require a minimum of eight transactions per week and at least two transactions of the same size in order to compute the imputed round-trip cost.

- Effective bid-ask spread, proposed in Hong and Warga (2000), is the most restrictive of our measures. It is the difference between the average sell and the average buy price, normalized by their mid-price:

$$
\text { EffSpread }{ }_{t}^{i}=\frac{2\left(\bar{P}_{t}^{i, \text { sell }}-\bar{P}_{t}^{i, \text { buy }}\right)}{\bar{P}_{t}^{i, \text { sell }}+\bar{P}_{t}^{i, \text { buy }}}
$$

where $\bar{P}_{t}^{i, \text { sell }}=\frac{1}{N_{t}^{i, \text { sell }}} \sum_{j=1}^{N_{t}^{i, \text { sell }}} P_{t}^{i, j}$ is the average sell price and idem for the average buy price $\bar{P}_{t}^{i, \text { buy }}$ of bond $i$ in week $t$. While the trade sign (buy/sell) is provided in TRACE, for our German sample it needs to be inferred following the algorithm of Lee and Ready (1991), by making use of quotes from Bloomberg. Therefore, for this measure, we not only require Bloomberg quotes, but also eight trades which must include at least one buy and sell trade each. In our case, it is possible to obtain negative values for the 
effective bid-ask spread since we infer the trade sign from daily data, but average over one week. We discard all such negative values. ${ }^{34}$

\footnotetext{
${ }^{34}$ For example, we could observe buys on the first day, following which the bond price falls and the bond is sold again at a lower price later in the same week.
} 
Table 1: Data cleaning and sample selection: Panel A shows the number of observations after each of the cleaning steps described in section 4.2. Before cleaning is the initial number of observations. We discard observations with errors in ISIN or timestamp, in non-debt securities, in minor currencies, corresponding to technical lines (duplicate lines that are automatically created by some reporting systems when the trade is on hold) or corresponding to double-reporting by both parties of a trade. Filtering is applied for prices (absolute values and weekly price median filter) and complete CFI codes (for bond classification). Panel B describes the number of bonds, observations and traded volume retained in our sample selection process. Vanilla bonds are bonds with a complete CFI code with fixed or zero coupon and a fixed redemption date and that are not classified otherwise as hybrid or structured products. Vanilla bonds are distinguished into secured/guaranteed bonds (secured through assets or a non-government entity), treasury-type bonds (issued or guaranteed by a federal or state government) and unsecured bonds. For unsecured bonds we distinguish between certificates and corporate bonds which are either financial bonds or non-financial bonds depending on the issuer type. Our German sample is based on data reported to the German Federal Financial Supervisory Authority (Bundesanstalt für Finanzdienstleistungsaufsicht, popularly known as "BaFin") from 2008 to 2014. For the U.S. sample we use the TRACE Enhanced database for the same period.

Panel A: Data cleaning

\begin{tabular}{rrrrrrrrrr}
\hline & $\begin{array}{r}\text { before } \\
\text { year }\end{array}$ & \multicolumn{3}{c}{ cleaning } & errors & non-debt & after removing & & \multicolumn{2}{c}{ after } & \multicolumn{2}{c}{ complete } & vanilla \\
currencies & technical lines & double-reporting & price-filtering & CFI code & bonds \\
\hline 2008 & $3,802,701$ & $3,766,085$ & $3,461,772$ & $3,428,490$ & $2,416,096$ & $1,597,236$ & $1,588,700$ & $1,522,319$ & $1,261,461$ \\
2009 & $3,675,045$ & $3,670,634$ & $3,263,093$ & $3,242,910$ & $1,706,814$ & $1,197,506$ & $1,189,079$ & $1,114,034$ & 845,341 \\
2010 & $4,106,918$ & $4,106,149$ & $3,989,344$ & $3,965,796$ & $2,019,035$ & $1,486,864$ & $1,478,227$ & $1,343,649$ & 935,190 \\
2011 & $3,770,269$ & $3,769,170$ & $3,678,184$ & $3,658,141$ & $2,072,979$ & $1,429,922$ & $1,421,010$ & $1,297,610$ & 928,948 \\
2012 & $4,681,385$ & $4,681,196$ & $4,573,035$ & $4,543,243$ & $2,695,704$ & $1,765,453$ & $1,723,423$ & $1,584,035$ & 961,130 \\
2013 & $4,258,139$ & $4,258,136$ & $4,122,257$ & $4,077,110$ & $2,670,584$ & $1,711,202$ & $1,687,676$ & $1,497,546$ & 965,263 \\
2014 & $4,077,082$ & $4,077,070$ & $3,818,136$ & $3,747,882$ & $2,426,399$ & $1,574,867$ & $1,554,282$ & $1,351,927$ & 843,248 \\
\hline$\sum$ & $28,371,539$ & $28,328,440$ & $26,905,821$ & $26,663,572$ & $16,007,611$ & $10,763,050$ & $10,642,397$ & $9,711,120$ & $6,740,581$ \\
\hline & & & & & & & Table 1 continued on next page.
\end{tabular}


Table 1 continued from previous page.

Panel B: Sample selection

\begin{tabular}{|c|c|c|c|c|c|c|c|c|}
\hline & \multirow[b]{2}{*}{ vanilla bonds } & \multicolumn{3}{|c|}{ vanilla bonds } & \multicolumn{2}{|c|}{ unsecured bonds } & \multicolumn{2}{|c|}{ corporate bonds } \\
\hline & & secured & treasury-type & unsecured & certificates & corporates & non-financial & financial \\
\hline \multicolumn{9}{|l|}{ WPHG: all trades } \\
\hline \# bonds & 81,664 & 4,873 & 4,218 & 72,573 & 60,817 & 11,670 & 817 & 10,853 \\
\hline \# trades & $6,740,581$ & $1,188,767$ & $2,906,710$ & $2,645,104$ & 765,781 & $1,857,777$ & 738,839 & $1,118,938$ \\
\hline traded volume (million EUR) & $12,474,668$ & 791,973 & $11,244,802$ & 437,893 & 29,901 & 389,294 & 57,209 & 332,085 \\
\hline \multicolumn{9}{|l|}{ WPHG: trades in German bonds } \\
\hline \# bonds & 65,819 & 2,803 & 1,272 & 61,744 & 51,938 & 9,741 & 178 & 9,563 \\
\hline \# trades & $4,216,200$ & 661,076 & $1,287,824$ & $2,267,300$ & 671,381 & $1,578,591$ & 581,594 & 996,997 \\
\hline traded volume (million EUR) & $7,572,336$ & 488,579 & $6,732,304$ & 351,453 & 20,863 & 319,454 & 34,879 & 284,575 \\
\hline \multicolumn{9}{|l|}{ TRACE } \\
\hline \# bonds & 9,602 & 598 & 274 & 8,730 & & 8,730 & 2,314 & 6,414 \\
\hline \# trades & $16,810,039$ & 319,396 & 414,914 & $16,075,729$ & & $16,075,729$ & $3,537,977$ & $12,537,466$ \\
\hline traded volume (million USD) & $6,865,837$ & 195,225 & 274,333 & $6,396,279$ & & $6,396,279$ & $1,605,194$ & $4,790,566$ \\
\hline
\end{tabular}


Table 2: Descriptive statistics of bond characteristics for German and U.S. corporate bonds, differentiated for financial and non-financial sector bonds. Coupon rate is in percent, excluding zero coupon-bonds. Maturity is the maturity at issuance, in years. Time to maturity) is the average remaining maturity at the time of a trade (averaged for each bond), in years. Amount issued is the issued amount of a bond in million EUR or USD respectively. Average number of trades per day is the average number of trades on any given trading day for the lifetime of the security. Average number of trades per day if trade is the average number of trades on a trading day with at least one trade. Average trading interval is the average amount of calendar days between two consecutive trades. Average daily volume is the average volume in million EUR (USD) traded on one day. Average daily volume if trade is the average volume in million EUR (USD) traded on a trading day with at least one trade. Trade volume total is the summed value of trades recorded in our sample for a given security, in million EUR or USD respectively. Our German sample is based on data reported to the German Federal Financial Supervisory Authority (Bundesanstalt für Finanzdienstleistungsaufsicht, popularly known as "BaFin") from 2008 to 2014. For the U.S. sample we use the TRACE Enhanced database for the same period.

\begin{tabular}{|c|c|c|c|c|c|c|c|c|c|c|}
\hline & \multicolumn{5}{|c|}{ German bonds, WpHG } & \multicolumn{5}{|c|}{ U.S. bonds, TRACE } \\
\hline & mean & stddev & p05 & median & p95 & mean & stddev & p05 & median & p95 \\
\hline \multicolumn{11}{|l|}{ non-financial bonds } \\
\hline Coupon rate $(\%)$ & 6.32 & 1.80 & 3.21 & 6.61 & 9.00 & 5.94 & 2.48 & 1.50 & 6.05 & 9.88 \\
\hline Maturity (years) & 5.89 & 2.32 & 3.02 & 5.00 & 10.00 & 13.71 & 12.44 & 2.48 & 10.02 & 30.08 \\
\hline Time to maturity (years) & 4.11 & 2.21 & 1.14 & 4.00 & 7.88 & 1.53 & 4.65 & 0.00 & 0.02 & 7.88 \\
\hline Amount issued (millions) & 146.63 & 236.47 & 2.17 & 30.00 & 700.00 & 406.49 & 633.17 & 12.92 & 250.00 & $1,250.00$ \\
\hline Avg. \# trades per day & 5.22 & 7.11 & 0.01 & 2.45 & 18.48 & 0.42 & 1.23 & 0.00 & 0.04 & 2.16 \\
\hline Avg. \# trades per day $\mid$ trade & 6.55 & 6.67 & 1.25 & 4.20 & 18.18 & 11.67 & 25.75 & 1.33 & 3.02 & 62.00 \\
\hline Avg. trading interval (days) & 12.75 & 34.23 & 1.44 & 1.89 & 56.14 & 22.06 & 69.49 & 1.46 & 5.00 & 91.34 \\
\hline Avg. daily volume (millions) & 0.33 & 0.68 & 0.00 & 0.09 & 1.42 & 0.22 & 0.63 & 0.00 & 0.02 & 1.06 \\
\hline Avg. daily volume / trade (millions) & 0.49 & 0.82 & 0.01 & 0.20 & 1.71 & 28.81 & 399.01 & 0.06 & 2.22 & 122.75 \\
\hline Total trade volume (millions) & 195.95 & 313.37 & 0.11 & 54.66 & 925.15 & 693.69 & $2,054.87$ & 0.73 & 86.78 & $3,077.17$ \\
\hline \multicolumn{11}{|l|}{ financial bonds } \\
\hline Coupon rate $(\%)$ & 5.36 & 4.30 & 1.45 & 3.87 & 15.00 & 5.16 & 1.70 & 2.00 & 5.30 & 7.55 \\
\hline Maturity (years) & 4.02 & 2.87 & 1.07 & 3.25 & 10.00 & 8.53 & 7.99 & 1.05 & 5.04 & 25.06 \\
\hline Time to maturity (years) & 2.45 & 2.38 & 0.22 & 1.41 & 7.20 & 0.98 & 2.90 & 0.00 & 0.01 & 5.35 \\
\hline Amount issued (millions) & 47.89 & 203.17 & 0.10 & 17.01 & 139.00 & 229.28 & 511.28 & 10.53 & 24.73 & $1,250.00$ \\
\hline Avg. \# trades per day & 0.18 & 0.70 & 0.00 & 0.02 & 0.78 & 0.70 & 2.01 & 0.00 & 0.14 & 3.44 \\
\hline Avg. \# trades per day $\mid$ trade & 1.60 & 1.28 & 1.00 & 1.20 & 3.39 & 4.97 & 8.37 & 1.00 & 2.96 & 16.15 \\
\hline Avg. trading interval (days) & 64.11 & 125.24 & 2.82 & 25.07 & 245.32 & 18.75 & 49.62 & 1.48 & 5.41 & 72.63 \\
\hline Avg. daily volume (millions) & 0.06 & 0.30 & 0.00 & 0.00 & 0.21 & 0.32 & 1.41 & 0.00 & 0.01 & 1.72 \\
\hline Avg. daily volume | trade (millions) & 3.63 & 25.48 & 0.00 & 0.07 & 14.60 & 4.11 & 25.81 & 0.04 & 0.16 & 15.27 \\
\hline Total trade volume (millions) & 29.76 & 135.91 & 0.00 & 1.11 & 119.58 & 746.89 & $2,911.20$ & 0.28 & 20.63 & $4,007.97$ \\
\hline
\end{tabular}


Table 3: Frequency of trading of corporate bonds: For German and U.S. non-financial and financial corporate bonds we report the number of days in a year that the bond is traded. For each bond we count the most active year. For example, of 178 German non-financial corporate bonds in our sample, 78 were traded on more than 200 days per year. Our German sample is based on data reported to the German Federal Financial Supervisory Authority (Bundesanstalt für Finanzdienstleistungsaufsicht, popularly known as "BaFin") from 2008 to 2014. For the U.S. sample we use the TRACE Enhanced database for the same period.

\begin{tabular}{lrrrrr}
\hline & \multicolumn{2}{c}{ German bonds, WpHG } & & U.S. bonds, TRACE \\
\cline { 2 - 3 } number of active days per year & non-financial & financial & & non-financial & financial \\
\hline $200+$ & 78 & 102 & 288 & 828 \\
$151-200$ & 15 & 147 & 161 & 524 \\
$101-150$ & 19 & 248 & & 197 & 865 \\
$51-100$ & 13 & 579 & 286 & 1,356 \\
$0-50$ & 53 & 8,487 & 1,382 & 2,841 \\
\hline$\sum$ & 178 & 9,563 & & 2,314 & 6,414 \\
\hline
\end{tabular}


Table 4: Descriptive statistics of bond characteristics for liquid German and U.S. corporate bonds, differentiated for financial and non-financial sector bonds. Coupon rate is in percent, excluding zero coupon-bonds. Maturity is the maturity at issuance, in years. Time to maturity) is the average remaining maturity at the time of a trade (averaged for each bond), in years. Amount issued is the issued amount of a bond in million EUR or USD respectively. Average number of trades per day is the average number of trades on any given trading day for the lifetime of the security. Average number of trades per day if trade is the average number of trades on a trading day with at least one trade. Average trading interval is the average amount of calendar days between two consecutive trades. Average daily volume is the average volume in million EUR (USD) traded on one day. Average daily volume if trade is the average volume in million EUR (USD) traded on a trading day with at least one trade. Trade volume total is the summed value of trades recorded in our sample for a given security, in million EUR or USD respectively. Our German sample is based on data reported to the German Federal Financial Supervisory Authority (Bundesanstalt für Finanzdienstleistungsaufsicht, popularly known as "BaFin") from 2008 to 2014. For the U.S. sample we use the TRACE Enhanced database for the same period.

\begin{tabular}{|c|c|c|c|c|c|c|c|c|c|c|}
\hline & \multicolumn{5}{|c|}{ German bonds, WpHG } & \multicolumn{5}{|c|}{ U.S. bonds, TRACE } \\
\hline & mean & stddev & p05 & median & p95 & mean & stddev & p05 & median & p95 \\
\hline \multicolumn{11}{|l|}{ non-financial bonds } \\
\hline Coupon rate $(\%)$ & 6.00 & 1.77 & 2.93 & 6.50 & 8.50 & 6.12 & 2.27 & 2.13 & 6.13 & 9.88 \\
\hline Maturity (years) & 5.81 & 2.00 & 4.00 & 5.00 & 10.00 & 14.35 & 12.61 & 4.15 & 10.02 & 30.10 \\
\hline Time to maturity (years) & 4.06 & 1.71 & 1.31 & 4.02 & 6.61 & 4.76 & 6.19 & 0.00 & 1.85 & 18.07 \\
\hline Amount issued (millions) & 183.42 & 264.41 & 5.00 & 50.00 & 757.50 & 477.75 & 682.65 & 14.99 & 300.00 & 1300.00 \\
\hline Avg. \# trades per day & 6.92 & 7.45 & 0.11 & 4.34 & 20.32 & 0.51 & 1.42 & 0.00 & 0.04 & 2.94 \\
\hline Avg. \# trades per day $\mid$ trade & 7.90 & 7.04 & 1.60 & 5.41 & 20.28 & 30.66 & 38.39 & 9.00 & 16.17 & 99.82 \\
\hline Avg. trading interval (calendar days) & 4.52 & 8.99 & 1.44 & 1.73 & 19.60 & 76.74 & 148.82 & 7.00 & 27.22 & 309.63 \\
\hline Avg. daily volume (millions) & 0.46 & 0.80 & 0.01 & 0.16 & 1.66 & 0.26 & 0.70 & 0.00 & 0.03 & 1.33 \\
\hline Avg. daily volume trade (millions) & 0.55 & 0.83 & 0.02 & 0.30 & 1.71 & 49.57 & 474.12 & 0.22 & 11.31 & 166.96 \\
\hline Total trade volume (millions) & 269.58 & 353.44 & 2.91 & 108.07 & 948.85 & 824.26 & 2365.86 & 0.68 & 123.70 & 3679.08 \\
\hline \multicolumn{11}{|l|}{ financial bonds } \\
\hline Coupon rate $(\%)$ & 3.75 & 2.18 & 1.61 & 3.38 & 6.15 & 5.15 & 1.62 & 2.03 & 5.35 & 7.50 \\
\hline Maturity (years) & 4.57 & 2.75 & 1.19 & 4.09 & 10.00 & 11.03 & 8.13 & 2.04 & 10.00 & 30.02 \\
\hline Time to maturity (years) & 2.85 & 2.18 & 0.41 & 2.43 & 6.87 & 3.85 & 3.54 & 0.20 & 2.71 & 9.47 \\
\hline Amount issued (millions) & 72.58 & 151.35 & 2.36 & 27.00 & 250.00 & 311.92 & 591.74 & 10.71 & 31.31 & 1500.00 \\
\hline Avg. \# trades per day & 0.73 & 1.33 & 0.04 & 0.31 & 2.69 & 0.89 & 2.40 & 0.01 & 0.13 & 5.14 \\
\hline Avg. \# trades per day $\mid$ trade & 2.90 & 2.17 & 1.36 & 2.15 & 7.15 & 25.16 & 32.66 & 9.25 & 14.35 & 82.01 \\
\hline Avg. trading interval (calendar days) & 15.36 & 25.80 & 2.09 & 8.14 & 49.93 & 44.78 & 70.41 & 7.00 & 25.22 & 141.08 \\
\hline Avg. daily volume (millions) & 0.12 & 0.36 & 0.00 & 0.02 & 0.46 & 0.43 & 1.37 & 0.00 & 0.01 & 2.58 \\
\hline Avg. daily volume trade (millions) & 1.17 & 4.86 & 0.03 & 0.14 & 5.00 & 12.45 & 44.77 & 0.16 & 0.58 & 60.63 \\
\hline Total trade volume (millions) & 60.39 & 158.84 & 0.79 & 14.05 & 267.57 & 1050.43 & 3462.93 & 0.64 & 22.50 & 6109.19 \\
\hline
\end{tabular}


Table 5: Ratings of liquid bonds: Rating steps of corporate bonds in our sample of liquid bonds. Ratings for German corporate bonds are obtained via Bloomberg, Thomson Reuters or Bundesbank databases. Ratings for U.S. bonds are from Mergent ID. Bonds with a rating notch of 10 and better are investment grade. The sample is corporate bonds that are sufficiently actively traded and for which we calculate liquidity measures. Our German sample is based on data reported to the German Federal Financial Supervisory Authority (Bundesanstalt für Finanzdienstleistungsaufsicht, popularly known as "BaFin") from 2008 to 2014. For the U.S. sample we use the TRACE Enhanced database for the same period.

\begin{tabular}{|c|c|c|c|c|}
\hline \multirow[b]{2}{*}{ rating notch } & \multicolumn{2}{|c|}{ German bonds } & \multicolumn{2}{|c|}{ U.S. bonds } \\
\hline & non-financial & financial & non-financial & financial \\
\hline 1 (Aaa/AAA) & 0 & 64 & 58 & 368 \\
\hline $2(\mathrm{Aa} 1 / \mathrm{AA}+)$ & 0 & 38 & 59 & 348 \\
\hline $3(\mathrm{Aa} 2 / \mathrm{AA})$ & 0 & 117 & 17 & 365 \\
\hline 4 (Aa3/AA-) & 0 & 347 & 82 & 690 \\
\hline $5(\mathrm{~A} 1 / \mathrm{A}+)$ & 4 & 460 & 110 & 539 \\
\hline $6(\mathrm{~A} 2 / \mathrm{A})$ & 0 & 134 & 250 & 768 \\
\hline $7(\mathrm{~A} 3 / \mathrm{A}-)$ & 0 & 260 & 161 & 252 \\
\hline $8(\mathrm{Baa} 1 / \mathrm{BBB}+)$ & 7 & 34 & 145 & 106 \\
\hline $9(\mathrm{Baa} 2 / \mathrm{BBB})$ & 7 & 1 & 164 & 89 \\
\hline 10 (Baa3/BBB- $)$ & 7 & 17 & 115 & 99 \\
\hline $11(\mathrm{Ba} 1 / \mathrm{BB}+)$ & 1 & 0 & 41 & 262 \\
\hline $12(\mathrm{Ba} 2 / \mathrm{BB})$ & 1 & 2 & 59 & 67 \\
\hline 13 (Ba3/BB-) & 0 & 0 & 70 & 68 \\
\hline $14(\mathrm{~B} 1 / \mathrm{B}+)$ & 1 & 2 & 55 & 173 \\
\hline $15(\mathrm{~B} 2 / \mathrm{B})$ & 0 & 0 & 55 & 48 \\
\hline 16 (B3/B-) & 0 & 0 & 90 & 32 \\
\hline $17(\mathrm{Caa} 1 / \mathrm{CCC}+)$ & 0 & 0 & 46 & 9 \\
\hline 18 (Caa2/CCC) & 0 & 0 & 16 & 6 \\
\hline 19 (Caa3/CCC-) & 0 & 0 & 3 & 6 \\
\hline $20(\mathrm{Ca} / \mathrm{CC})$ & 0 & 0 & 0 & 1 \\
\hline $21(\mathrm{C} / \mathrm{C})$ & 0 & 0 & 2 & 0 \\
\hline unavailable & 90 & 109 & 146 & 453 \\
\hline$\sum$ & 118 & 1,585 & 1,744 & 4,749 \\
\hline
\end{tabular}


Table 6: Liquidity statistics: Summary statistics of liquidity measures of German and U.S. corporate bonds. Panel A shows statistics for non-financial bonds and Panel B for financial bonds. Amihud is the Amihud measure of price impact obtained as the mean ratio of absolute log returns to trade volumes. Price dispersion is the root mean squared difference between traded prices and the market valuation proxied by the volume-weighted average trade price. Roll is the Roll measure, a proxy for the round-trip cost and obtained as twice the square root of the negative auto-covariance of returns. Effective bid-ask spread is the difference between the average sell and the average buy price, normalized by their mid-price. The trade sign (buy/sell) is inferred by comparing to quotes from Bloomberg. Imputed round-trip cost proxies bid-ask spread by comparing the highest to the lowest price of a set of transactions with identical volumes. All measures were computed for every bond and week where there were at least eight trades with sufficient information available and winsorized at the $0.5 \%$ and $99.5 \%$ quantile. Units are basis points except for the Amihud measure, which is given as in units of basis points per million EUR (USD) for German bonds (U.S. bonds). Our German sample is based on data reported to the German Federal Financial Supervisory Authority (Bundesanstalt für Finanzdienstleistungsaufsicht, popularly known as "BaFin") from 2008 to 2014. For the U.S. sample we use the TRACE Enhanced database for the same period.

Panel A: Non-financial bonds

\begin{tabular}{|c|c|c|c|c|c|c|c|}
\hline & mean & stddev & p05 & median & p95 & \# bonds & \# bond-weeks \\
\hline \multicolumn{8}{|c|}{ German non-financial bonds (WpHG) } \\
\hline Amihud (bp per million EUR) & 349.47 & 1447.58 & 5.17 & 42.96 & 1210.15 & 118 & 11,057 \\
\hline Price Dispersion (bp) & 57.41 & 59.35 & 8.61 & 38.02 & 177.66 & 118 & 11,045 \\
\hline Roll Measure (bp) & 67.25 & 50.61 & 15.01 & 54.18 & 167.02 & 118 & 10,674 \\
\hline Effective Bid-Ask (bp) & 81.65 & 109.63 & 11.00 & 48.78 & 282.32 & 87 & 6,278 \\
\hline Imputed Roundtrip (bp) & 120.18 & 176.15 & 9.73 & 58.38 & 516.45 & 118 & 10,922 \\
\hline \multicolumn{8}{|c|}{ U.S. non-financial bonds (TRACE) } \\
\hline Amihud (bp per million USD) & 77.43 & 115.73 & 1.41 & 40.63 & 273.84 & 1,658 & 85,580 \\
\hline Price Dispersion (bp) & 90.27 & 110.88 & 10.28 & 57.80 & 263.07 & 1,658 & 85,580 \\
\hline Roll Measure (bp) & 128.86 & 124.76 & 16.87 & 94.84 & 346.51 & 1,625 & 79,086 \\
\hline Effective Bid-Ask (bp) & 136.04 & 168.95 & 5.48 & 73.91 & 447.54 & 1,582 & 79,119 \\
\hline Imputed Roundtrip (bp) & 66.81 & 69.21 & 5.32 & 45.76 & 199.80 & 1,602 & 81,267 \\
\hline
\end{tabular}

Table 6 continued on next page. 
Table 6 continued from previous page.

Panel B: Financial bonds

\begin{tabular}{|c|c|c|c|c|c|c|c|}
\hline & mean & stddev & p05 & median & p95 & \# bonds & \# bond-weeks \\
\hline \multicolumn{8}{|l|}{ German financial bonds (WpHG) } \\
\hline Amihud (bp per million EUR) & 29.81 & 61.17 & 0.71 & 11.88 & 106.85 & 1,508 & 18,917 \\
\hline Price Dispersion (bp) & 34.69 & 34.41 & 3.00 & 24.85 & 98.42 & 1,508 & 18,744 \\
\hline Roll Measure (bp) & 53.84 & 50.63 & 3.65 & 39.24 & 153.58 & 1,508 & 17,945 \\
\hline Effective Bid-Ask (bp) & 102.62 & 92.88 & 12.33 & 77.71 & 270.45 & 323 & 3,048 \\
\hline Imputed Roundtrip (bp) & 45.83 & 53.53 & 2.75 & 29.26 & 143.59 & 1,476 & 17,253 \\
\hline \multicolumn{8}{|l|}{ U.S. financial bonds (TRACE) } \\
\hline Amihud (bp per million USD) & 110.88 & 190.21 & 3.45 & 51.96 & 401.21 & 4,318 & 276,466 \\
\hline Price Dispersion (bp) & 123.82 & 192.00 & 10.19 & 73.89 & 389.02 & 4,318 & 276,467 \\
\hline Roll Measure (bp) & 164.08 & 192.58 & 17.83 & 110.61 & 452.80 & 4,265 & 256,743 \\
\hline Effective Bid-Ask (bp) & 199.76 & 254.81 & 6.53 & 130.67 & 582.02 & 4,249 & 263,809 \\
\hline Imputed Roundtrip (bp) & 88.00 & 100.14 & 6.63 & 56.87 & 263.56 & 4,218 & 260,827 \\
\hline
\end{tabular}


Table 7: Determinants of liquidity: Regression of the liquidity measures described in Table 6, computed at weekly frequency, on bond and bond-time characteristics. The sample for Panel A are German corporate bonds that carry a rating and U.S. bonds with a rating for panel B. All liquidity measures are calculated for each bond on a weekly basis and winsorized at the $0.5 \%$ level from both tails. The explanatory variables are given by bond size (in million EUR/USD), rating notch (1 being the best rating on the scale, cf. Table 5), time to maturity (in years), age (in years), volume traded in the same bond and week (in million EUR/USD), and a dummy indicating whether the bond is issued by a financial firm. Yearfixed effects are included with the year 2014 as a baseline. Our German sample is based on data reported to the German Federal Financial Supervisory Authority (Bundesanstalt für Finanzdienstleistungsaufsicht, popularly known as "BaFin") from 2008 to 2014. For the U.S. sample we use the TRACE Enhanced database for the same period. Test statistics, derived from standard errors corrected for heteroscedasticity and clustered at the firm level, are given in parentheses. The significance is indicated as follows: ${ }^{*}<0.1,{ }^{* *}<0.05,{ }^{* * *}<0.01$.

Panel A: German liquid bonds

\begin{tabular}{|c|c|c|c|c|c|}
\hline & Price Dispersion & Roll & Amihud & Imputed Roundtr. & Eff. Bidask \\
\hline Bond size (million EUR) & $\begin{array}{c}0.005 \\
(0.991)\end{array}$ & $\begin{array}{c}0.010 \\
(1.104)\end{array}$ & $\begin{array}{c}-0.008 \\
(-1.246)\end{array}$ & $\begin{array}{c}0.013 \\
(1.357)\end{array}$ & $\begin{array}{l}-0.032^{* *} \\
(-2.294)\end{array}$ \\
\hline Rating notch & $\begin{array}{c}2.703^{* * *} \\
(3.439)\end{array}$ & $\begin{array}{c}2.754^{* * *} \\
(2.681)\end{array}$ & $\begin{array}{c}2.631 \\
(1.331)\end{array}$ & $\begin{array}{c}6.267^{* * *} \\
(3.553)\end{array}$ & $\begin{array}{c}3.257 \\
(1.339)\end{array}$ \\
\hline Time to maturity (years) & $\begin{array}{c}4.466^{* * *} \\
(4.661)\end{array}$ & $\begin{array}{c}7.853^{* * *} \\
(4.631)\end{array}$ & $\begin{array}{c}1.599 \\
(1.275)\end{array}$ & $\begin{array}{c}6.307^{* * *} \\
(4.469)\end{array}$ & $\begin{array}{l}4.902^{* *} \\
(2.324)\end{array}$ \\
\hline Age (years) & $\begin{array}{l}1.294^{* *} \\
(2.485)\end{array}$ & $\begin{array}{c}3.154^{* * *} \\
(3.591)\end{array}$ & $\begin{array}{l}2.664^{* *} \\
(2.319)\end{array}$ & $\begin{array}{l}2.602^{* *} \\
(2.258)\end{array}$ & $\begin{array}{c}-1.913 \\
(-0.886)\end{array}$ \\
\hline Volume (million EUR) & $\begin{array}{c}0.029 \\
(0.989)\end{array}$ & $\begin{array}{l}-0.089^{*} \\
(-1.758)\end{array}$ & $\begin{array}{l}-0.171^{*} \\
(-1.959)\end{array}$ & $\begin{array}{l}-0.093^{* *} \\
(-2.538)\end{array}$ & $\begin{array}{l}-0.241^{*} \\
(-1.859)\end{array}$ \\
\hline Dummy: financial & $\begin{array}{c}17.694^{* * *} \\
(2.914)\end{array}$ & $\begin{array}{c}25.066^{* * *} \\
(3.184)\end{array}$ & $\begin{array}{l}12.430 \\
(1.196)\end{array}$ & $\begin{array}{c}32.080^{* * *} \\
(3.157)\end{array}$ & $\begin{array}{c}50.080^{* * *} \\
(4.868)\end{array}$ \\
\hline Dummy: year 2008 & $\begin{array}{c}12.684^{* * * *} \\
(3.179)\end{array}$ & $\begin{array}{c}5.508 \\
(0.566)\end{array}$ & $\begin{array}{c}-0.104 \\
(-0.015)\end{array}$ & $\begin{array}{c}14.300^{*} \\
(1.689)\end{array}$ & $\begin{array}{c}66.761^{* * *} \\
(6.677)\end{array}$ \\
\hline Dummy: year 2009 & $\begin{array}{c}13.408^{* * *} \\
(3.588)\end{array}$ & $\begin{array}{c}9.120 \\
(0.876)\end{array}$ & $\begin{array}{c}-3.639 \\
(-0.572)\end{array}$ & $\begin{array}{l}10.278 \\
(1.121)\end{array}$ & $\begin{array}{c}65.888^{* * *} \\
(5.379)\end{array}$ \\
\hline Dummy: year 2010 & $\begin{array}{l}8.307^{* *} \\
(2.458)\end{array}$ & $\begin{array}{c}9.298 \\
(0.860)\end{array}$ & $\begin{array}{c}-2.442 \\
(-0.413)\end{array}$ & $\begin{array}{c}5.366 \\
(0.664)\end{array}$ & $\begin{array}{c}36.318^{* * *} \\
(4.832)\end{array}$ \\
\hline Dummy: year 2011 & $\begin{array}{l}8.064^{*} \\
(1.866)\end{array}$ & $\begin{array}{c}4.367 \\
(0.356)\end{array}$ & $\begin{array}{c}0.209 \\
(0.026)\end{array}$ & $\begin{array}{c}8.857 \\
(0.884)\end{array}$ & $\begin{array}{c}42.605^{* * *} \\
(4.114)\end{array}$ \\
\hline Dummy: year 2012 & $\begin{array}{c}10.593^{* *} \\
(2.515)\end{array}$ & $\begin{array}{c}5.904 \\
(0.558)\end{array}$ & $\begin{array}{c}9.936 \\
(1.030)\end{array}$ & $\begin{array}{l}12.692 \\
(1.371)\end{array}$ & $\begin{array}{c}24.705^{* * *} \\
(3.213)\end{array}$ \\
\hline Dummy: year 2013 & $\begin{array}{c}3.912 \\
(1.506)\end{array}$ & $\begin{array}{c}6.279 \\
(1.060)\end{array}$ & $\begin{array}{c}2.307 \\
(0.568)\end{array}$ & $\begin{array}{c}6.901 \\
(1.562)\end{array}$ & $\begin{array}{c}9.088 \\
(1.470)\end{array}$ \\
\hline Constant & $\begin{array}{c}-23.173^{*} \\
(-1.856)\end{array}$ & $\begin{array}{l}-20.737 \\
(-1.277) \\
\end{array}$ & $\begin{array}{c}-4.062 \\
(-0.163) \\
\end{array}$ & $\begin{array}{c}-53.029^{* *} \\
(-2.271) \\
\end{array}$ & $\begin{array}{c}-2.586 \\
(-0.081) \\
\end{array}$ \\
\hline Observations & 21,439 & 20,691 & 21,599 & 19,965 & 5,709 \\
\hline number of bonds & 1,391 & 1,343 & 1,411 & 1,341 & 305 \\
\hline $\mathrm{R}^{2}$ & 0.090 & 0.123 & 0.029 & 0.104 & 0.251 \\
\hline Adjusted $\mathrm{R}^{2}$ & 0.089 & 0.123 & 0.029 & 0.103 & 0.250 \\
\hline
\end{tabular}


Table 7 continued from previous page.

Panel B: TRACE liquid bonds

\begin{tabular}{|c|c|c|c|c|c|}
\hline & Price Dispersion & Roll & Amihud & Imputed Roundtr. & Eff. Bidask \\
\hline Bond size (million USD) & $\begin{array}{c}-0.018^{* * *} \\
(-3.631)\end{array}$ & $\begin{array}{c}-0.012^{* * *} \\
(-3.423)\end{array}$ & $\begin{array}{c}-0.022^{* * *} \\
(-5.365)\end{array}$ & $\begin{array}{c}-0.011^{* * *} \\
(-5.478)\end{array}$ & $\begin{array}{c}-0.062^{* * *} \\
(-6.560)\end{array}$ \\
\hline Rating notch & $\begin{array}{c}12.407^{* * *} \\
(8.504)\end{array}$ & $\begin{array}{c}8.300^{* * * *} \\
(7.027)\end{array}$ & $\begin{array}{c}4.849^{* * *} \\
(4.048)\end{array}$ & $\begin{array}{c}3.612^{* * *} \\
(5.989)\end{array}$ & $\begin{array}{c}11.218^{* * *} \\
(3.979)\end{array}$ \\
\hline Time to maturity (years) & $\begin{array}{l}3.906^{* * *} \\
(10.006)\end{array}$ & $\begin{array}{l}5.946^{* * *} \\
(16.419)\end{array}$ & $\begin{array}{l}4.644^{* * *} \\
(11.519)\end{array}$ & $\begin{array}{l}3.669^{* * *} \\
(13.845)\end{array}$ & $\begin{array}{c}6.181^{* * *} \\
(10.940\end{array}$ \\
\hline Age (years) & $\begin{array}{c}0.931 \\
(0.979)\end{array}$ & $\begin{array}{c}0.845 \\
(1.061)\end{array}$ & $\begin{array}{c}3.705^{* * *} \\
(3.563)\end{array}$ & $\begin{array}{c}0.301 \\
(1.029)\end{array}$ & $\begin{array}{c}2.779^{* * *} \\
(2.776\end{array}$ \\
\hline Volume (million USD) & $\begin{array}{c}0.032 \\
(1.397)\end{array}$ & $\begin{array}{l}-0.005 \\
(-0.295)\end{array}$ & $\begin{array}{l}-0.051^{* *} \\
(-2.316)\end{array}$ & $\begin{array}{c}-0.004 \\
(-0.383)\end{array}$ & $\begin{array}{c}-0.153^{* * *} \\
(-2.678\end{array}$ \\
\hline Dummy: financial & $\begin{array}{c}44.110^{* * *} \\
(7.518)\end{array}$ & $\begin{array}{c}45.167^{* * *} \\
(9.030)\end{array}$ & $\begin{array}{c}46.378^{* * *} \\
(7.460)\end{array}$ & $\begin{array}{c}27.453^{* * *} \\
(9.603)\end{array}$ & $\begin{array}{c}80.162^{* * *} \\
(8.799\end{array}$ \\
\hline Dummy: year 2008 & $\begin{array}{c}179.640^{* * *} \\
(10.094)\end{array}$ & $\begin{array}{c}168.019^{* * *} \\
(13.168)\end{array}$ & $\begin{array}{c}142.558^{* * *} \\
(9.656)\end{array}$ & $\begin{array}{c}82.966^{* * *} \\
(15.139)\end{array}$ & $\begin{array}{c}190.142^{* * *} \\
(7.803\end{array}$ \\
\hline Dummy: year 2009 & $\begin{array}{c}146.160^{* * *} \\
(14.781)\end{array}$ & $\begin{array}{c}125.867^{* * *} \\
(17.150)\end{array}$ & $\begin{array}{c}107.225^{* * *} \\
(15.604)\end{array}$ & $\begin{array}{c}72.495^{* * *} \\
(17.675)\end{array}$ & $\begin{array}{c}165.765^{* * *} \\
(13.161\end{array}$ \\
\hline Dummy: year 2010 & $\begin{array}{c}25.115^{* * *} \\
(3.562)\end{array}$ & $\begin{array}{c}40.329^{* * *} \\
(6.833)\end{array}$ & $\begin{array}{c}37.112^{* * *} \\
(6.236)\end{array}$ & $\begin{array}{c}25.934^{* * *} \\
(8.697)\end{array}$ & $\begin{array}{c}38.944^{* * *} \\
(4.237\end{array}$ \\
\hline Dummy: year 2011 & $\begin{array}{c}24.103^{* * *} \\
(4.212)\end{array}$ & $\begin{array}{c}33.459^{* * *} \\
(6.194)\end{array}$ & $\begin{array}{c}30.538^{* * *} \\
(5.770)\end{array}$ & $\begin{array}{c}21.168^{* * *} \\
(6.702)\end{array}$ & $\begin{array}{c}34.972^{* * *} \\
(4.455\end{array}$ \\
\hline Dummy: year 2012 & $\begin{array}{l}8.979^{*} \\
(1.856)\end{array}$ & $\begin{array}{c}13.384^{* * *} \\
(4.925)\end{array}$ & $\begin{array}{l}6.927^{* *} \\
(2.535)\end{array}$ & $\begin{array}{c}9.131^{* * *} \\
(6.217)\end{array}$ & $\begin{array}{c}21.325^{* * *} \\
(3.976\end{array}$ \\
\hline Dummy: year 2013 & $\begin{array}{l}1.848 \\
(0.510)\end{array}$ & $\begin{array}{l}2.119 \\
(0.773)\end{array}$ & $\begin{array}{l}-1.729 \\
(-0.718)\end{array}$ & $\begin{array}{l}1.491 \\
(0.957)\end{array}$ & $\begin{array}{l}2.979 \\
(0.553\end{array}$ \\
\hline Constant & $\begin{array}{c}-90.503^{* * *} \\
(-5.798)\end{array}$ & $\begin{array}{c}-52.730^{* * *} \\
(-3.864)\end{array}$ & $\begin{array}{c}-56.609^{* * *} \\
(-4.055)\end{array}$ & $\begin{array}{c}-21.936^{* * *} \\
(-3.326)\end{array}$ & $\begin{array}{c}-57.717^{* *} \\
(-2.134\end{array}$ \\
\hline Observations & 357,132 & 357,132 & 357,132 & 344,871 & 357,132 \\
\hline number of bonds & 5,660 & 5,660 & 5,660 & 5,617 & 5,660 \\
\hline $\mathrm{R}^{2}$ & 0.322 & 0.265 & 0.206 & 0.281 & 0.306 \\
\hline Adjusted $\mathrm{R}^{2}$ & 0.322 & 0.265 & 0.206 & 0.281 & 0.306 \\
\hline
\end{tabular}


Table 8: Propensity score matched regressions: Regression of the liquidity measures described in Table 6, computed at weekly frequency, on bond and bond-time characteristics. All liquidity measures are calculated for each bond on a weekly basis and winsorized at the $0.5 \%$ level from both tails. The sample is a matched sample of German corporate bonds that carry a rating (treatment group) and a control group of U.S. bonds matched at weekly frequency based on amount outstanding, time to maturity, maturity at issuance, rating, coupon rate, average trade volume and classification as financial bond. See section 5.2.4 for details of the matching process. The explanatory variables are given by bond size (in million EUR/USD), rating notch (1 being the best rating on the scale, cf. Table 5), time to maturity (in years), age (in years), a dummy indicating whether the bond is issued by a financial firm and a dummy indicating whether a bond is part of the German (treatment) sample. Year-fixed effects are included with the year 2014 as a baseline. Our German sample is based on data reported to the German Federal Financial Supervisory Authority (Bundesanstalt für Finanzdienstleistungsaufsicht, popularly known as "BaFin") from 2008 to 2014. For the U.S. sample we use the TRACE Enhanced database for the same period. Test statistics, derived from standard errors corrected for heteroscedasticity and clustered at the firm level, are given in parentheses. The significance is indicated as follows: ${ }^{*}<0.1,{ }^{* *}<0.05,{ }^{* * *}<0.01$.

\begin{tabular}{lccccc}
\hline & Price Dispersion & Roll & Amihud & Imputed Roundtr. & Eff. Bidask \\
\hline Bond size (million USD) & $-0.016^{* * *}$ & -0.003 & $-0.021^{* * *}$ & $-0.007^{* *}$ & $-0.052^{* * *}$ \\
& $(-3.064)$ & $(-0.949)$ & $(-4.256)$ & $(-2.121)$ & $(-6.437)$ \\
Rating notch & $5.069^{* * *}$ & $3.984^{* * *}$ & $4.338^{* * *}$ & $2.337^{* * *}$ & $4.489^{* * *}$ \\
& $(4.204)$ & $(4.194)$ & $(5.354)$ & $(5.014)$ & $(3.542)$ \\
Time to maturity (years) & $5.219^{* * *}$ & $7.839^{* * *}$ & $5.095^{* * *}$ & $4.517^{* * *}$ & $7.965^{* * *}$ \\
& $(9.108)$ & $(14.310)$ & $(7.904)$ & $(10.009)$ & $(8.904)$ \\
Age (years) & $3.803^{* * *}$ & $2.951^{* * *}$ & $4.536^{* * *}$ & $1.837^{* * *}$ & $4.309^{* * *}$ \\
& $(3.943)$ & $(3.698)$ & $(5.848)$ & $(3.153)$ & $(3.322)$ \\
Dummy: financial & $36.185^{* * *}$ & $32.859^{* * *}$ & $23.159^{* * *}$ & $17.542^{* * *}$ & $57.792^{* * *}$ \\
& $(4.000)$ & $(4.511)$ & $(4.462)$ & $(3.927)$ & $(5.538)$ \\
Dummy: German sample & $-61.086^{* * *}$ & $-47.244^{* * *}$ & $-40.740^{* * *}$ & -3.440 & $-39.205^{* * *}$ \\
& $(-8.645)$ & $(-8.709)$ & $(-6.338)$ & $(-0.770)$ & $(-3.990)$ \\
Dummy: year 2008 & $79.200^{* * *}$ & $72.015^{* * *}$ & $56.490^{* * *}$ & $37.268^{* * *}$ & $95.339^{* * *}$ \\
& $(6.490)$ & $(5.932)$ & $(6.596)$ & $(5.962)$ & $(7.530)$ \\
Dummy: year 2009 & $68.928^{* * *}$ & $55.675^{* * *}$ & $36.686^{* * *}$ & $30.345^{* * *}$ & $103.809^{* * *}$ \\
& $(6.586)$ & $(5.614)$ & $(4.880)$ & $(4.705)$ & $(6.871)$ \\
Dummy: year 2010 & $23.029^{* * *}$ & $26.132^{* * *}$ & $17.533^{* * *}$ & $12.064^{* * *}$ & $41.652^{* * *}$ \\
& $(4.084)$ & $(3.780)$ & $(2.861)$ & $(2.737)$ & $(5.489)$ \\
Dummy: year 2011 & $19.059^{* * *}$ & $16.843^{* *}$ & $11.481^{*}$ & $11.223^{* *}$ & $39.515^{* * *}$ \\
& $(3.616)$ & $(2.376)$ & $(1.774)$ & $(2.257)$ & $(5.110)$ \\
Dummy: year 2012 & $13.475^{* * *}$ & $13.682^{* *}$ & 4.862 & $9.208^{*}$ & $21.421^{* * *}$ \\
& $(2.861)$ & $(2.136)$ & $(0.753)$ & $(1.865)$ & $(3.221)$ \\
Dummy: year 2013 & 4.003 & $7.326^{* *}$ & -0.363 & 1.553 & 1.114 \\
& $(1.346)$ & $(2.120)$ & $(-0.068)$ & $(0.499)$ & $(0.219)$ \\
Constant & -23.277 & -12.365 & -17.160 & -6.134 & -1.264 \\
& $(-1.304)$ & $(-0.836)$ & $(-1.558)$ & $(-0.747)$ & $(-0.066)$ \\
\hline Observations & 29,108 & 28,116 & 29,294 & 27,316 & 10,882 \\
number of bonds & 4,497 & 4,394 & 4,521 & 4,329 & 2,334 \\
$\mathrm{R}^{2}$ & 0.201 & 0.182 & 0.077 & 0.108 & 0.230 \\
Adjusted R ${ }^{2}$ & 0.201 & 0.181 & 0.076 & 0.108 & 0.229 \\
\hline
\end{tabular}


Figure 1: Number of liquid bonds: Number of bonds for which we compute liquidity measures at the weekly level. The sample Panel (a) are German non-financial bonds and German financial bonds for Panel (b). Price dispersion, Roll measure, Amihud measure and imputed round-trip cost require eight observed trades. The calculation of the effective bid-ask spread for our German sample further requires the availability of quotes to infer whether a trade was buyer- or seller-initiated, leading to fewer observations. Year-end effects are clearly discernible in all transaction-based measures of liquidity. For U.S. bonds in Panel (c) the trade sign is included in TRACE, and we distinguish only between financial and non-financial bonds. Our German sample is based on data reported to the German Federal Financial Supervisory Authority (Bundesanstalt für Finanzdienstleistungsaufsicht, popularly known as "BaFin") from 2008 to 2014. For the U.S. sample we use the TRACE Enhanced database for the same period.

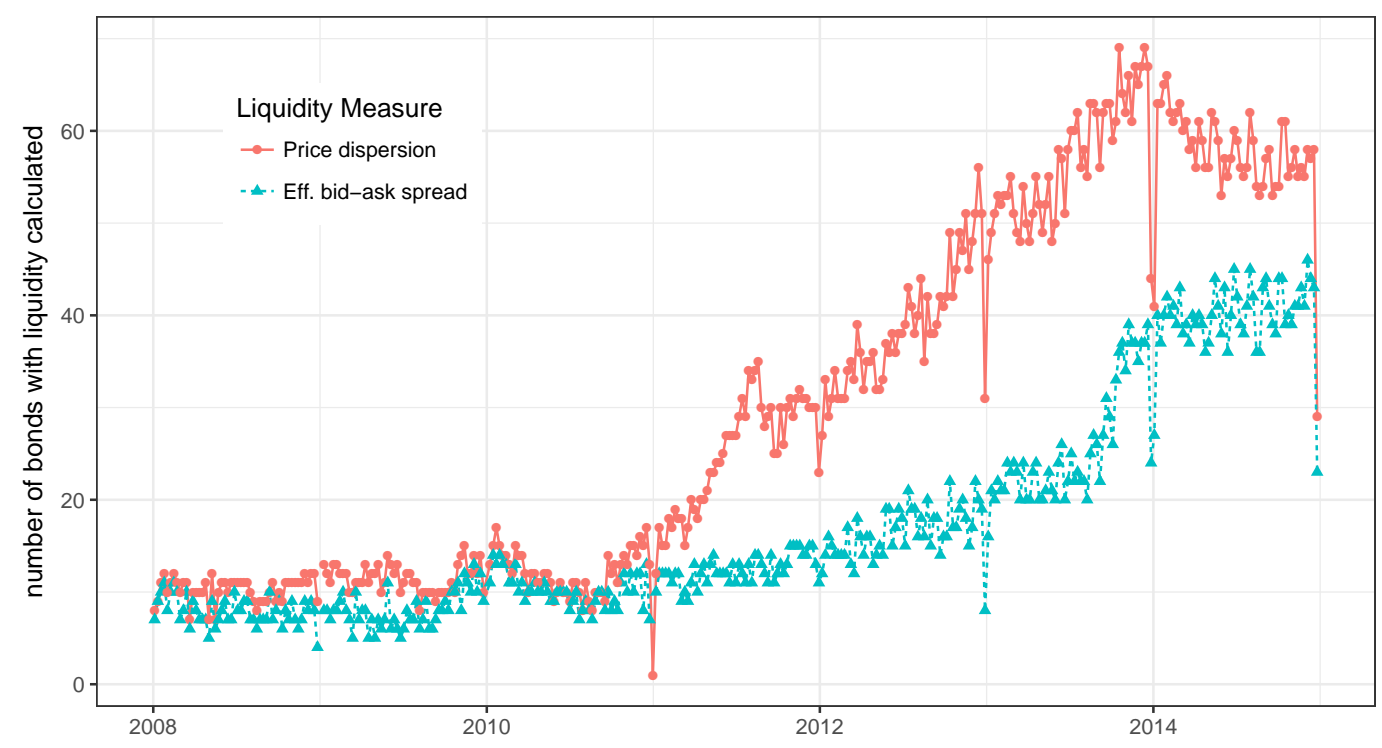

(a) German non-financial bonds (WpHG)

Figure 1 continued on next page. 
Figure 1 continued from previous page.

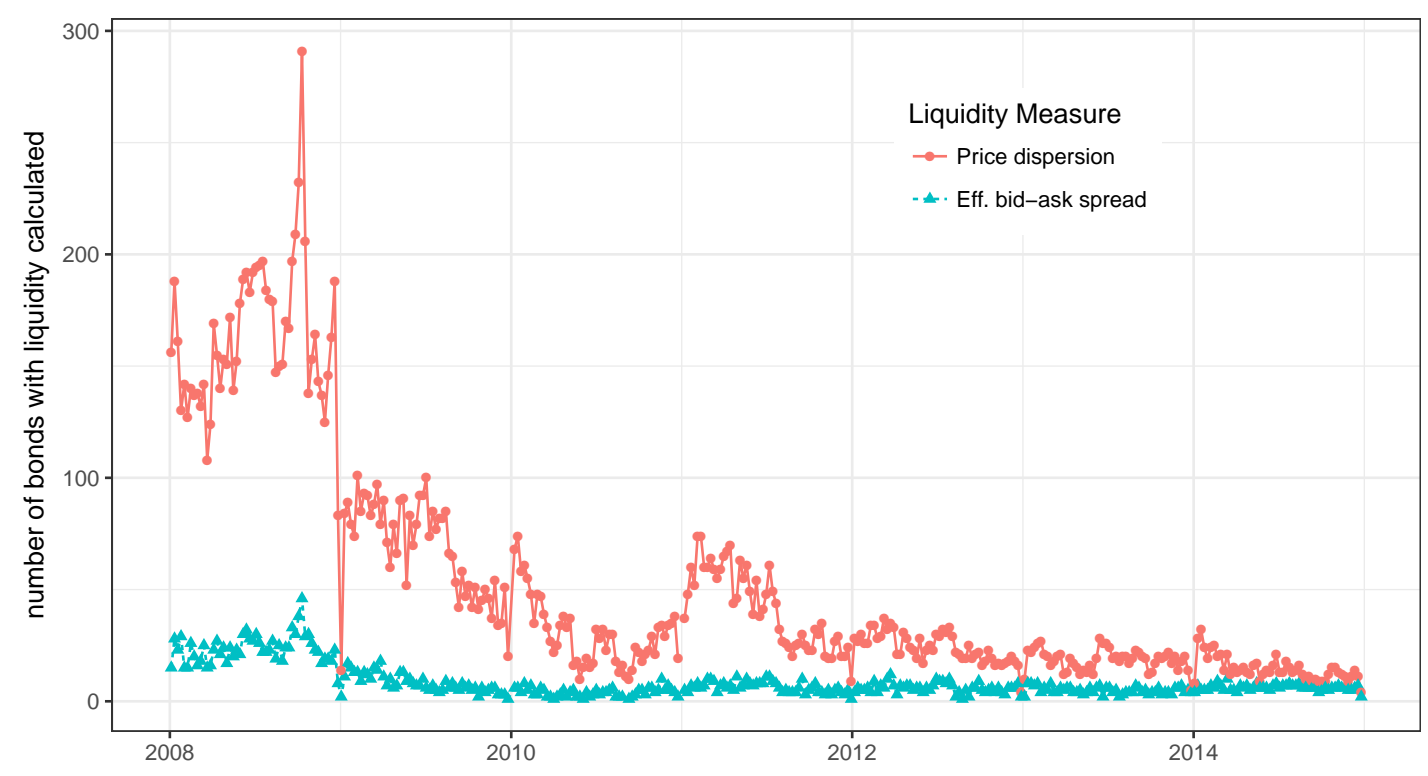

(b) German financial bonds (WpHG)

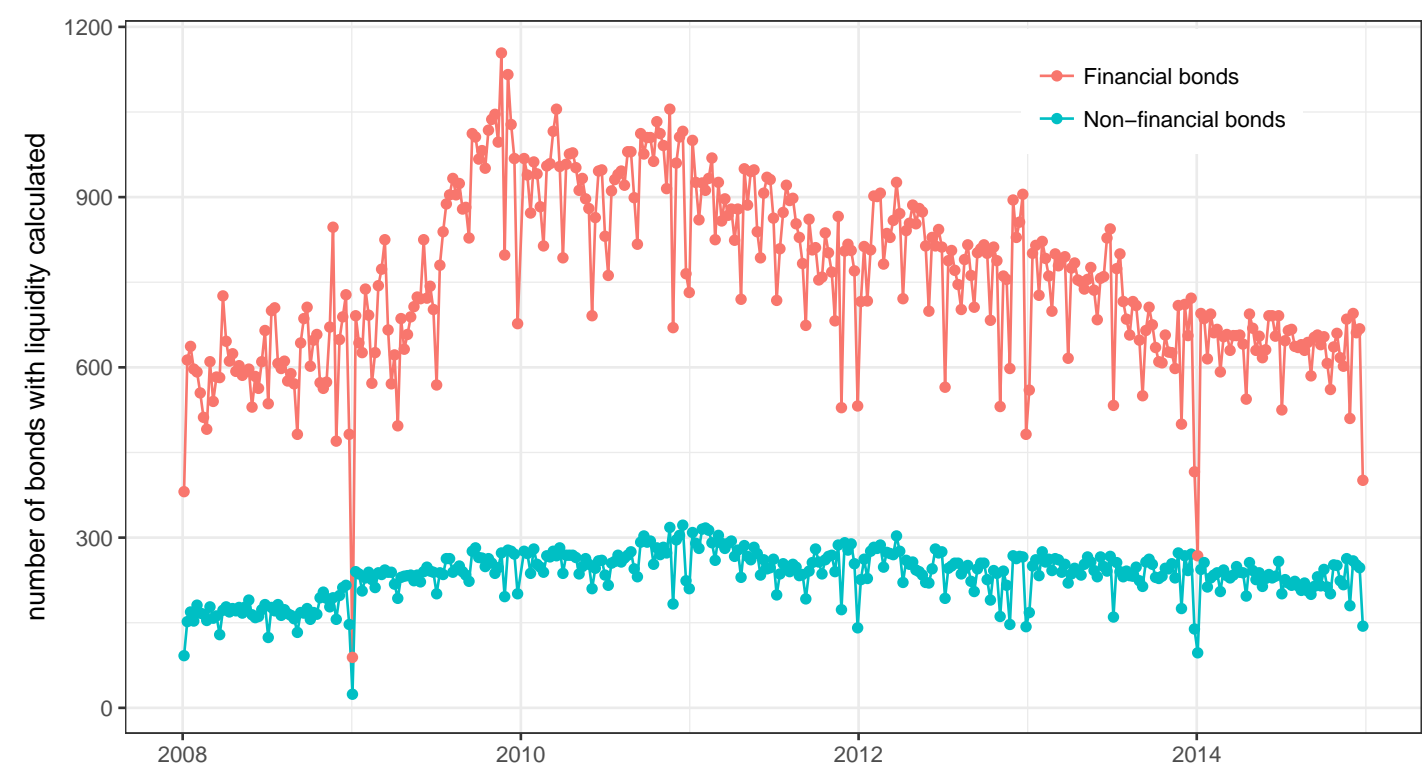

(c) U.S. bonds (TRACE) 
Figure 2: Effective bid-ask spread: Effective bid-ask spread is the difference between the average sell and the average buy price, normalized by their mid-price and given in basis points. Our German sample is based on data reported to the German Federal Financial Supervisory Authority (Bundesanstalt für Finanzdienstleistungsaufsicht, popularly known as "BaFin") from 2008 to 2014. For the U.S. sample we use the TRACE Enhanced database for the same period.

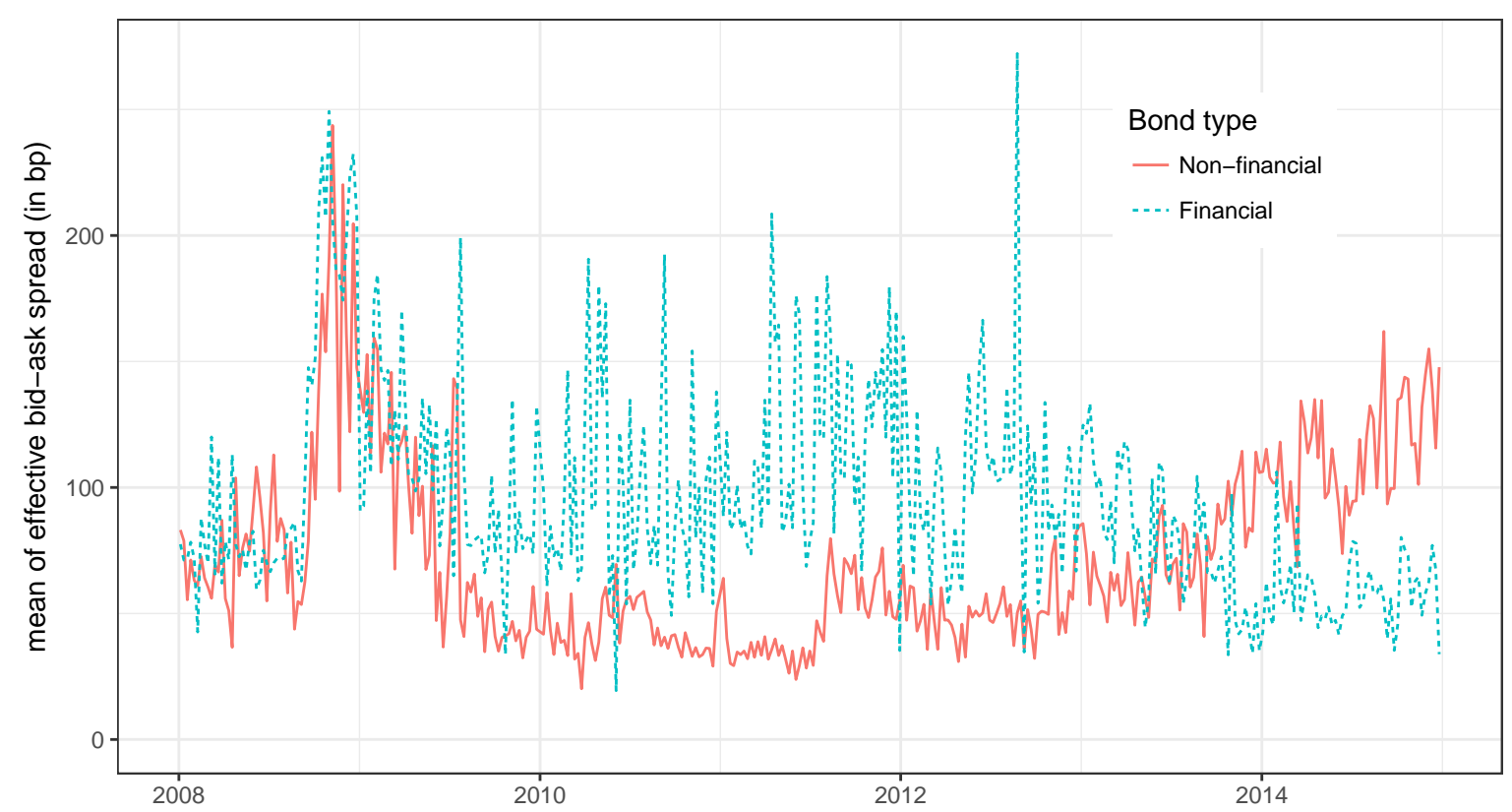

(a) German bonds (WpHG data).

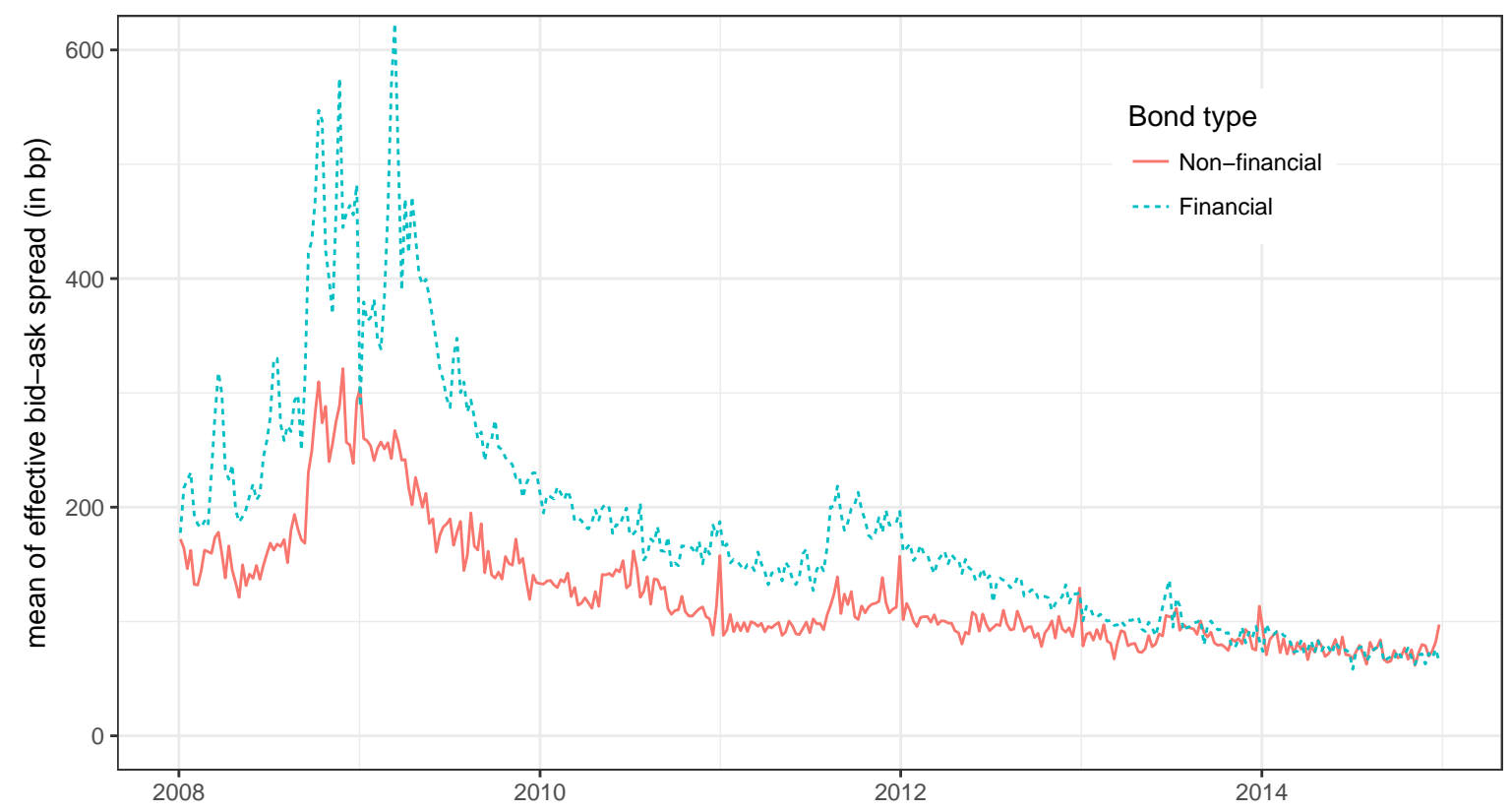

(b) U.S. bonds (TRACE data). 
Figure 3: Further liquidity measures - German bonds. Price dispersion is the root mean squared difference between traded prices and the market valuation proxied by the volume-weighted average trade price. Roll is a proxy for the round-trip cost and is obtained as twice the square root of the negative auto-covariance of returns. Imputed round-trip cost proxies bid-ask spread by comparing the highest to the lowest price of a set of transactions with identical volumes. Amihud is a measure of price impact obtained as the mean ratio of absolute log returns to trade volumes. All measures are given in basis points except for the Amihud, which is given in units of basis points per million EUR of trade volume. Our German sample is based on data reported to the German Federal Financial Supervisory Authority (Bundesanstalt für Finanzdienstleistungsaufsicht, popularly known as "BaFin") from 2008 to 2014.

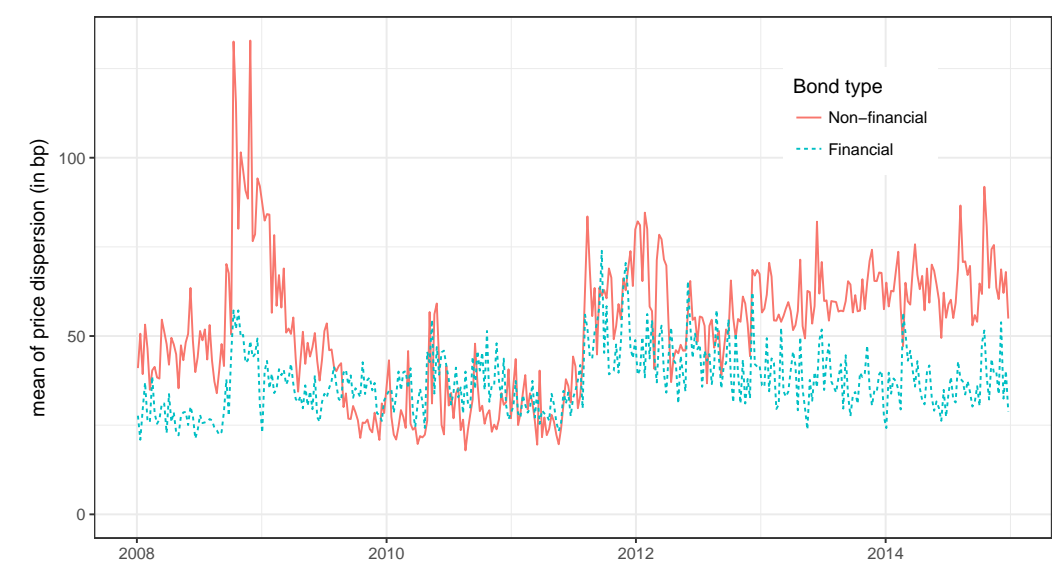

(a) Price dispersion

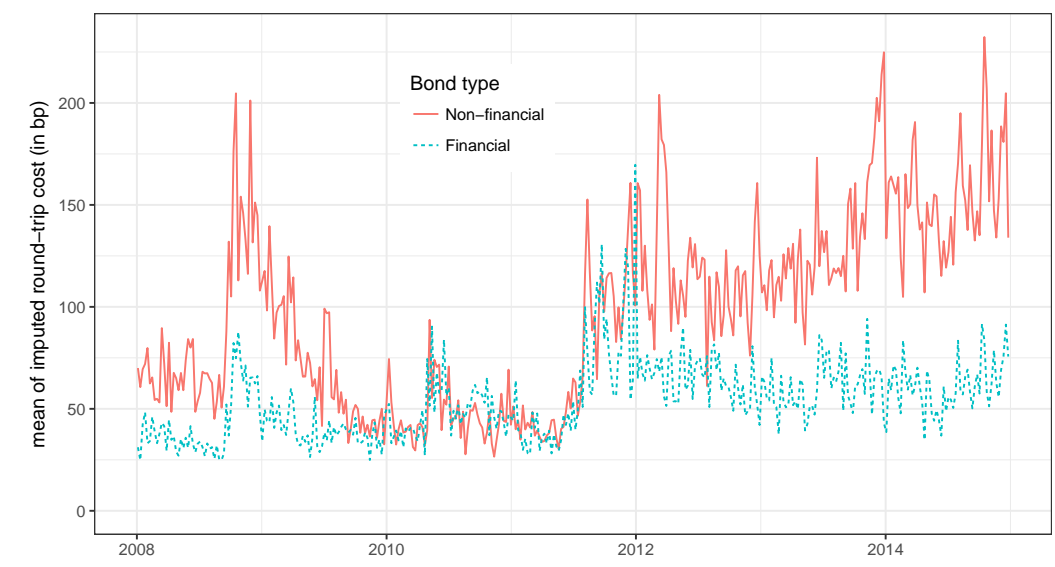

(c) Imputed round-trip cost

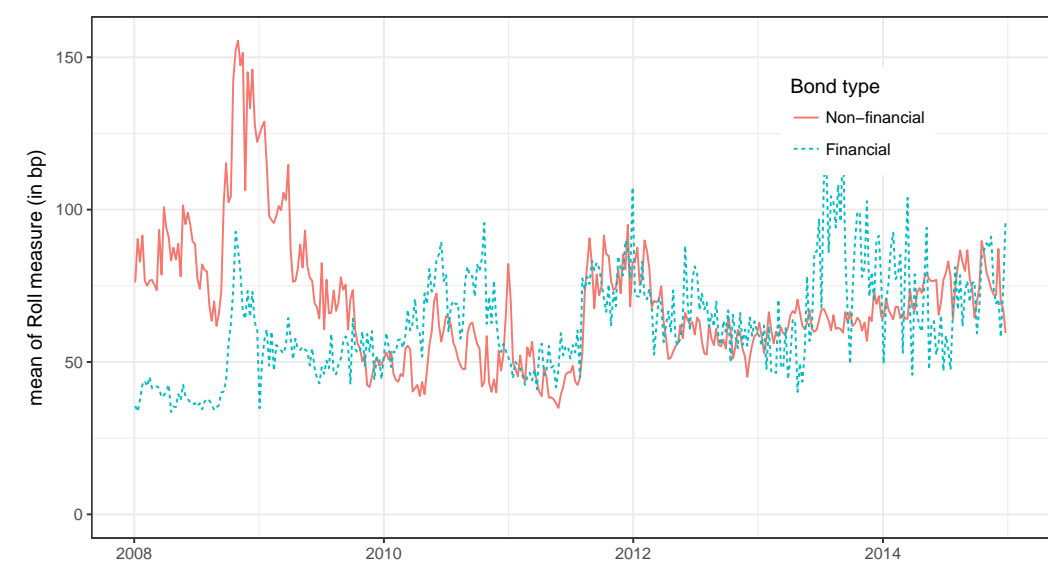

(b) Roll measure

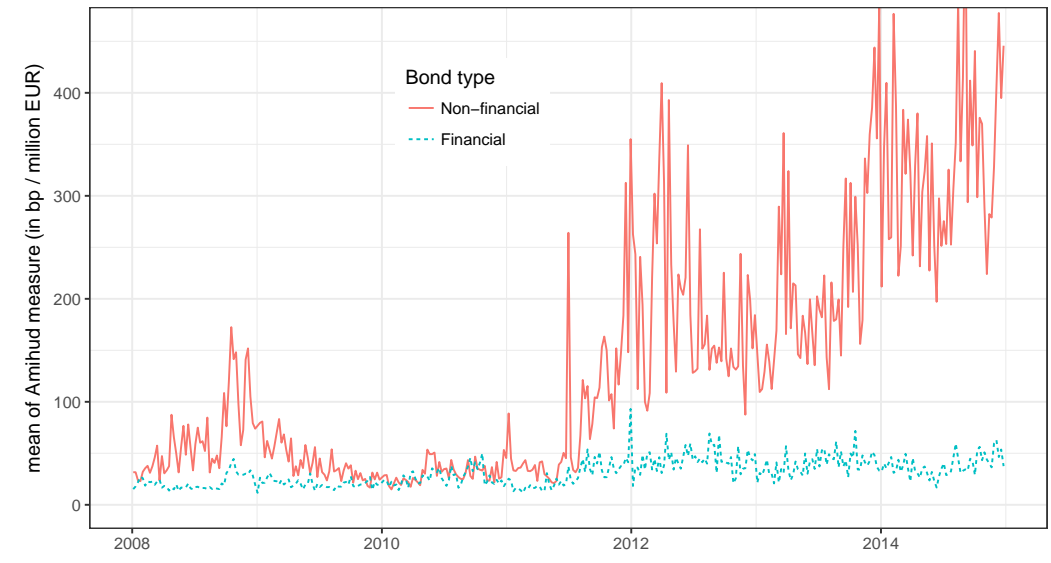

(d) Amihud measure 
Figure 4: Further liquidity measures - U.S. bonds. Price dispersion is the root mean squared difference between traded prices and the market valuation proxied by the volume-weighted average trade price. Roll is a proxy for the round-trip cost and is obtained as twice the square root of the negative auto-covariance of returns. Imputed round-trip cost proxies bid-ask spread by comparing the highest to the lowest price of a set of transactions with identical volumes. Amihud is a measure of price impact obtained as the mean ratio of absolute log returns to trade volumes. All measures are given in basis points except for the Amihud, which is given in units of basis points per million USD of trade volume. Our U.S. sample is based on the TRACE Enhanced database for the period from 2008 to 2014.

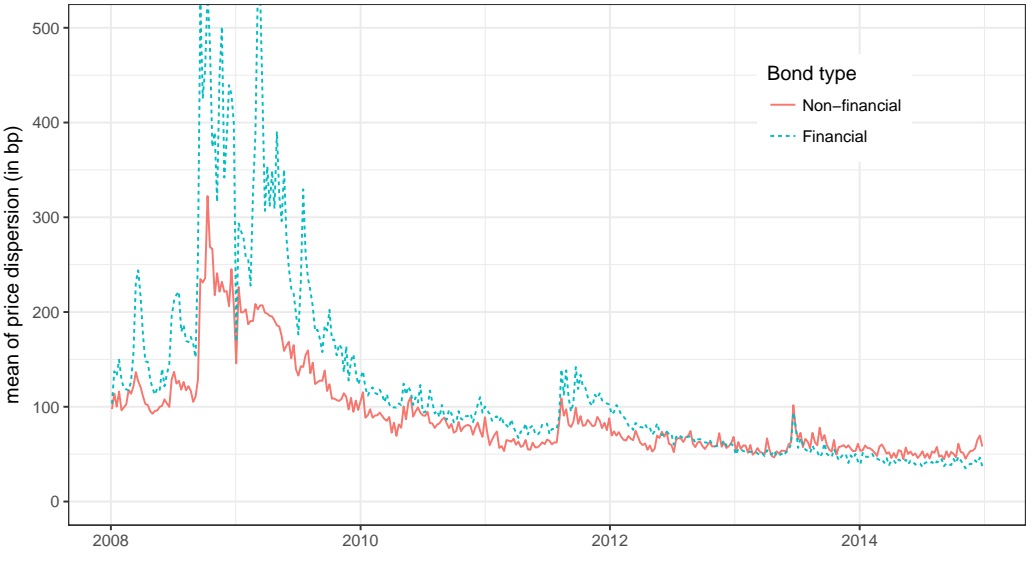

(a) Price dispersion

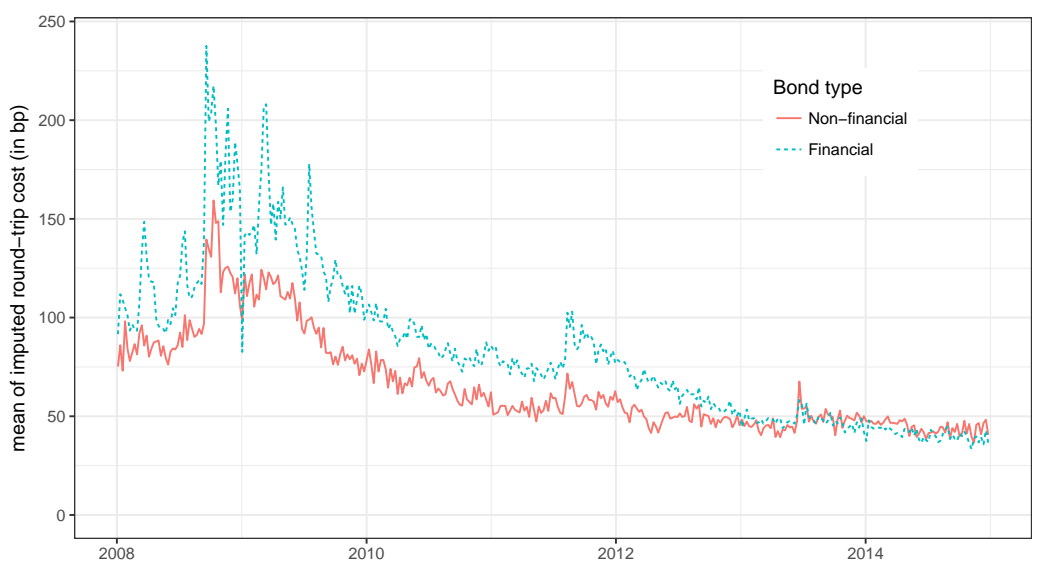

(c) Imputed round-trip cost

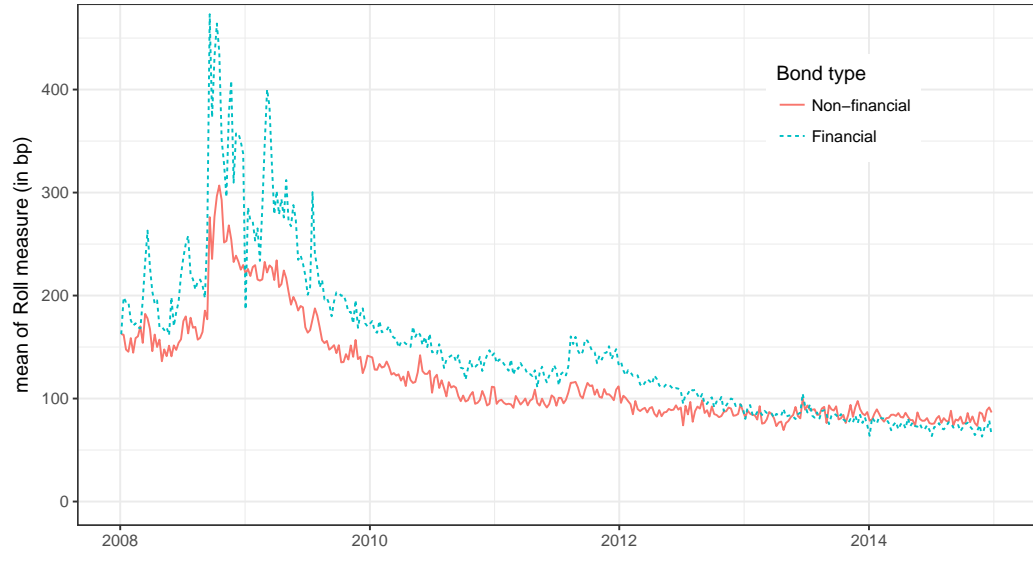

(b) Roll measure

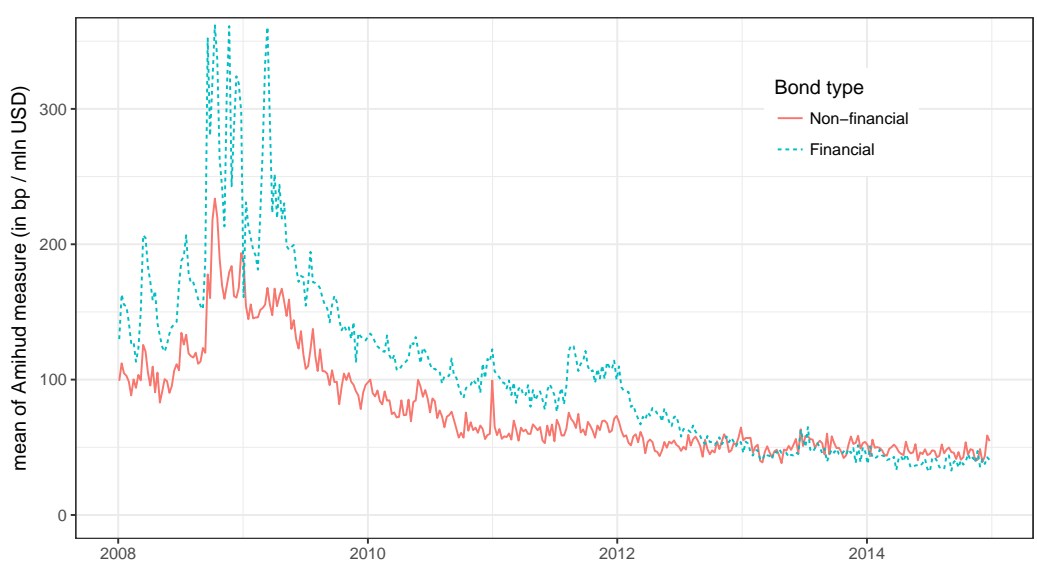

(d) Amihud measure 
Internet Appendix

Internet Appendix to

Lighting up the Dark: Liquidity in the German Corporate Bond Market 
Table I1: Data Cleaning Process - TRACE: This table illustrates the data cleaning process and the number and share of observations remaining after each cleaning step for each year of data and the whole dataset. The data sample comes from TRACE Enhanced and covers the period January 2008 - December 2014. When necessary, bond characteristics are matched from MERGENT FISD. The initial number of observations is given as before cleaning. TRACE filter: In the first cleaning step we clean the transaction data of errors using the algorithm described in Dick-Nielsen (2009). In particular, we delete duplicates, trade corrections and trade cancellations on the same day. Moreover, we remove reversals, which are errors detected on a day later than that of the initial trade. Price filter: Additionally, we implement the price filters described in Friewald, Jankowitsch, and Subrahmanyam (2012). Specifically, we adopt a reversal filter, which eliminates extreme price movements, and a median filter, which identifies outliers in prices reported in TRACE within a given time period.

\begin{tabular}{rrrrrr}
\hline year & before cleaning & TRACE filter & \% of raw & price filter & \% of raw \\
\hline 2008 & $8,982,733$ & $5,791,024$ & $64 \%$ & $5,766,619$ & $64 \%$ \\
2009 & $15,509,609$ & $9,968,885$ & $64 \%$ & $9,847,259$ & $63 \%$ \\
2010 & $16,196,597$ & $9,710,084$ & $60 \%$ & $9,349,861$ & $58 \%$ \\
2011 & $14,866,634$ & $9,044,960$ & $61 \%$ & $8,610,110$ & $58 \%$ \\
2012 & $16,552,442$ & $9,908,571$ & $60 \%$ & $9,211,178$ & $56 \%$ \\
2013 & $16,276,111$ & $9,691,278$ & $60 \%$ & $8,898,621$ & $55 \%$ \\
2014 & $15,224,322$ & $9,115,658$ & $60 \%$ & $8,239,993$ & $54 \%$ \\
\hline$\sum$ & $103,608,448$ & $63,230,460$ & $61 \%$ & $59,923,641$ & $58 \%$ \\
\hline
\end{tabular}


Table I2: Liquidity correlation: Correlation of weekly means of liquidity measures for German corporate bonds. Amihud is the Amihud measure of price impact obtained as the mean ratio of absolute log returns to trade volumes. Price dispersion is the root mean squared difference between traded prices and the market valuation proxied by the volume-weighted average trade price. Roll is the Roll measure, a proxy for the round-trip cost and obtained as twice the square root of the negative auto-covariance of returns. Effective bid-ask spread is the difference between the average sell and the average buy price, normalized by their midprice. The trade sign (buy/sell) is inferred following the algorithm of Lee and Ready (1991), by making use of quotes from Bloomberg. Imputed round-trip cost proxies bid-ask spread by comparing the highest to the lowest price of a set of transactions with identical volumes. All measures were computed for every bond and week where there were at least eight trades with sufficient information available and winsorized at the $0.5 \%$ and $99.5 \%$ quantile. Our German sample is based on data reported to the German Federal Financial Supervisory Authority (Bundesanstalt für Finanzdienstleistungsaufsicht, popularly known as "BaFin") from 2008 to 2014. For the U.S. sample we use the TRACE Enhanced database for the same period.

Panel A: in levels, all German liquid bonds

\begin{tabular}{lrrrrr}
\hline & Amihud & EffSpread & ImputedRTCost & PriceDisp & Roll \\
\hline Amihud & 1.00 & 0.25 & 0.88 & 0.69 & 0.51 \\
EffSpread & 0.25 & 1.00 & 0.26 & 0.32 & 0.32 \\
ImputedRTCost & 0.88 & 0.26 & 1.00 & 0.91 & 0.68 \\
PriceDisp & 0.69 & 0.32 & 0.91 & 1.00 & 0.77 \\
Roll & 0.51 & 0.32 & 0.68 & 0.77 & 1.00 \\
\hline
\end{tabular}

Panel B: in differences, all German liquid bonds

\begin{tabular}{lrrrrr}
\hline & Amihud & EffSpread & ImputedRTCost & PriceDisp & Roll \\
\hline Amihud & 1.00 & 0.13 & 0.40 & 0.14 & 0.14 \\
EffSpread & 0.13 & 1.00 & 0.24 & 0.33 & 0.15 \\
ImputedRTCost & 0.40 & 0.24 & 1.00 & 0.64 & 0.29 \\
PriceDisp & 0.14 & 0.33 & 0.64 & 1.00 & 0.40 \\
Roll & 0.14 & 0.15 & 0.29 & 0.40 & 1.00 \\
\hline
\end{tabular}

Panel C: in levels, all U.S. liquid bonds

\begin{tabular}{lrrrrr}
\hline & Amihud & EffSpread & ImputedRTCost & PriceDisp & Roll \\
\hline Amihud & 1.00 & 0.98 & 0.98 & 0.97 & 0.99 \\
EffSpread & 0.98 & 1.00 & 0.97 & 0.98 & 0.98 \\
ImputedRTCost & 0.98 & 0.97 & 1.00 & 0.96 & 0.98 \\
PriceDisp & 0.97 & 0.98 & 0.96 & 1.00 & 0.98 \\
Roll & 0.99 & 0.98 & 0.98 & 0.98 & 1.00 \\
\hline
\end{tabular}

Panel D: in differences, all U.S. liquid bonds

\begin{tabular}{lrrrrr}
\hline & Amihud & EffSpread & ImputedRTCost & PriceDisp & Roll \\
\hline Amihud & 1.00 & 0.81 & 0.88 & 0.90 & 0.90 \\
EffSpread & 0.81 & 1.00 & 0.76 & 0.77 & 0.73 \\
ImputedRTCost & 0.88 & 0.76 & 1.00 & 0.93 & 0.92 \\
PriceDisp & 0.90 & 0.77 & 0.93 & 1.00 & 0.93 \\
Roll & 0.90 & 0.73 & 0.92 & 0.93 & 1.00 \\
\hline
\end{tabular}


Figure I1: Monthly traded volume: summed monthly volume of all trades in German corporate bonds reported due to WpHG (Panel (a)) and in U.S. corporate bonds reported in TRACE (Panel (b)). Our German sample is based on data reported to the German Federal Financial Supervisory Authority (Bundesanstalt für Finanzdienstleistungsaufsicht, popularly known as "BaFin") from 2008 to 2014. For the U.S. sample we use the TRACE Enhanced database for the same period.

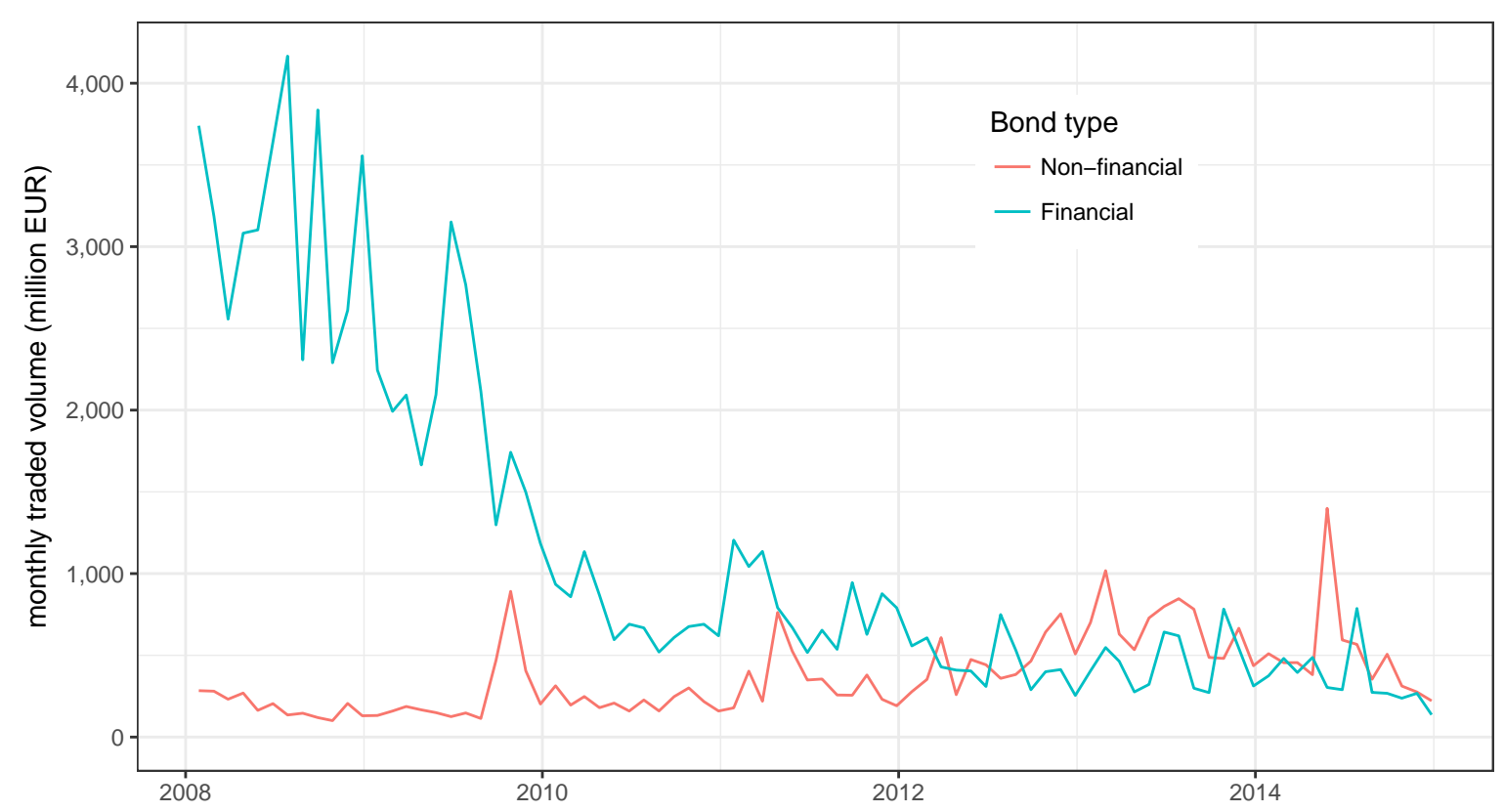

(a) Monthly traded volume in liquid German bonds.

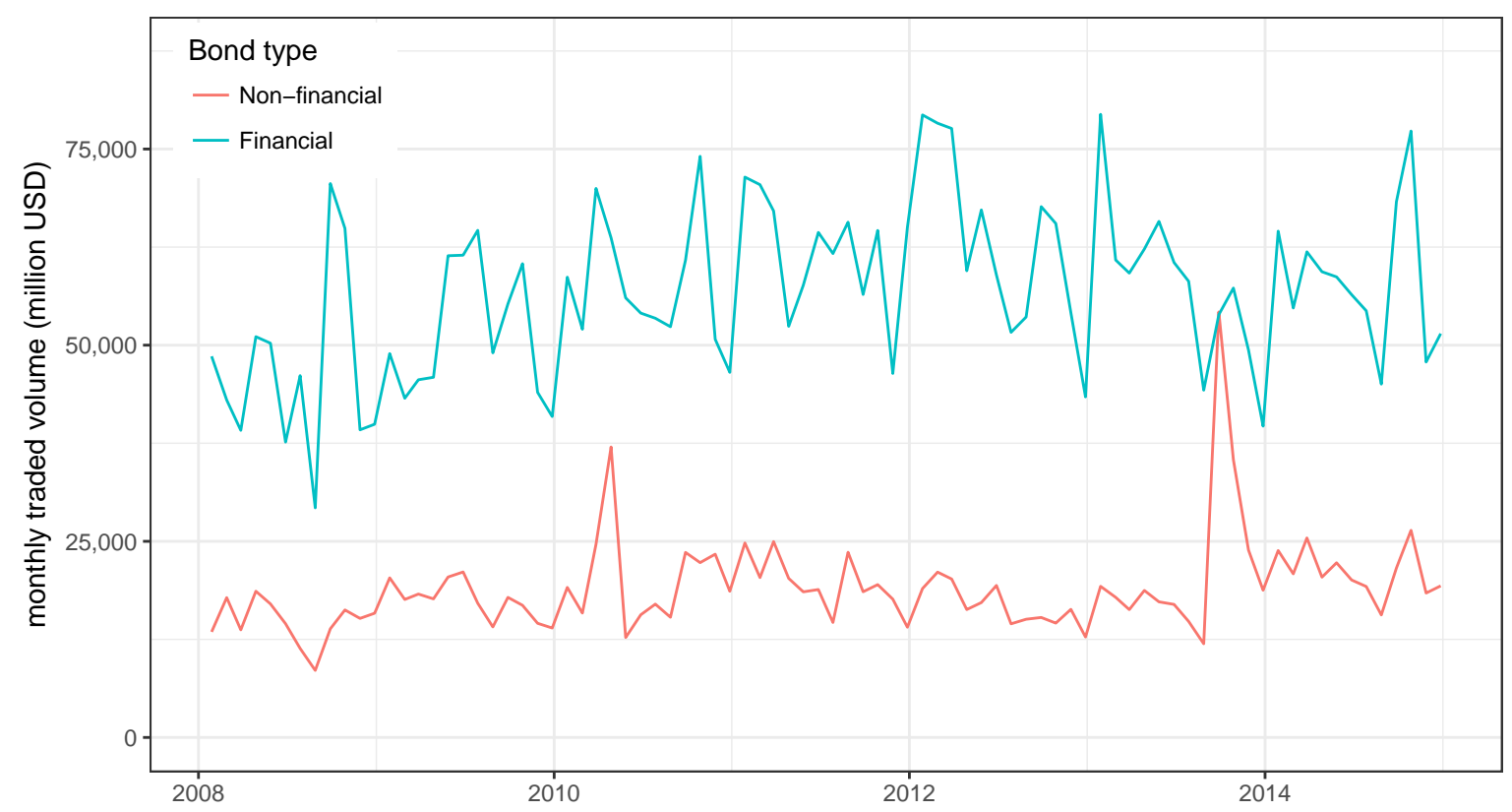

(b) Monthly traded volume in liquid U.S. bonds. 


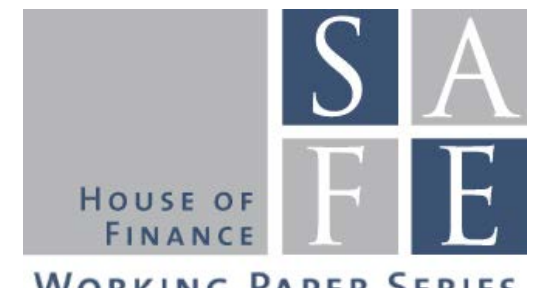

WORKING PAPER SERIES

\section{Recent Issues}

No. 229 Daniel Harenberg

No. 228 Roberto C. Panzica

No. 227 Mila Getmansky, Ravi

Jagannathan, Loriana Pelizzon,

Ernst Schaumburg, Darya Yuferova

No. 226 Loriana Pelizzon, Marti G.

Subrahmanyam, Davide Tomio, Jun Uno

No. 225 Monica Billio, Massimiliano Caporin, Lorenzo Frattarolo, Loriana Pelizzon

No. 224 Giulio Girardi, Kathleen W. Hanley, Stanislava Nikolova, Loriana Pelizzon, Mila Getmansky Sherman

No. 223 Florian Deuflhard

No. 222 Vanessa Endrejat, Matthias Thiemann

No. 221 Axel H. Börsch-Supan, Klaus Härtl, Duarte N. Leite, Alexander Ludwig

No. 220 Yangming Bao, Martin R. Goetz

No. 219 Andreas Hackethal - Christine Laudenbach - Steffen Meyer Annika Weber

No. 218 Florian Hoffmann, Roman Inderst, Marcus Opp
Asset Pricing in OLG Economies With Borrowing Constraints and Idiosyncratic Income Risk

Idiosyncratic Volatility Puzzle: The Role of Assets' Interconnections

Stock Price Crashes: Role of Slow-Moving Capital

\section{Central Bank-Driven Mispricing?}

Networks in risk spillovers:

A multivariate GARCH perspective

Portfolio Similarity and Asset Liquidation in the Insurance Industry

Quantifying Inertia in Retail Deposit Markets

Reviving the Shadow Banking Chain in Europe: Regulatory Agency, Technical Complexity and the Dynamics of CoHabitation

Endogenous Retirement Behavior of Heterogeneous Households Under Pension Reforms

Local Peer Effects and Corporate Investment

Client Involvement in Expert Advice Antibiotics in Finance?

Only Time will Tell: A Theory of Deferred Compensation 